ص ص[

$$
\begin{aligned}
& \text { أثر المديونية الخارجية في قيمة الموازين السلعية للحبوب }
\end{aligned}
$$

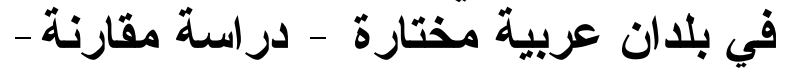

$$
\begin{aligned}
& \text { آمنة عبد الإله الحسون } \\
& \text { مدرس مساعد - قسم الاقتصاد الزراعي } \\
& \text { كلية الزراعة والغابات - جامعة الموصل }
\end{aligned}
$$

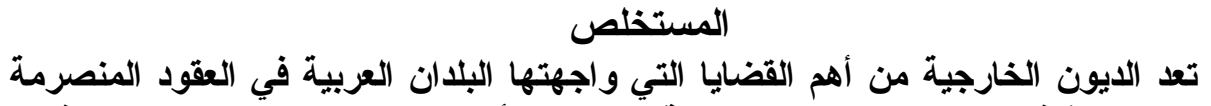

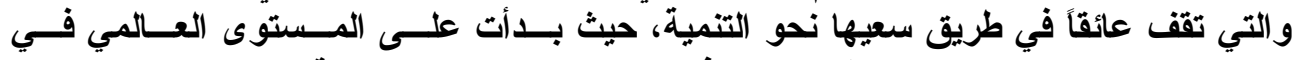

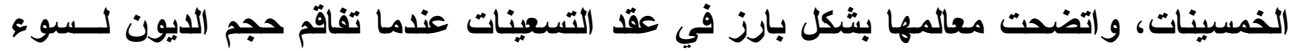

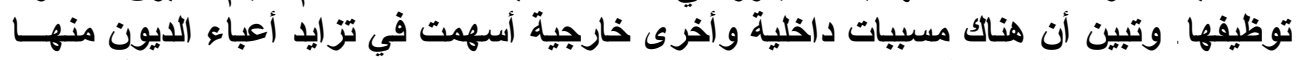

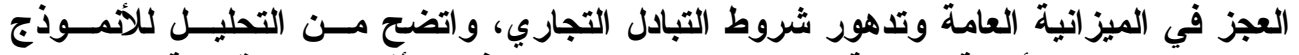

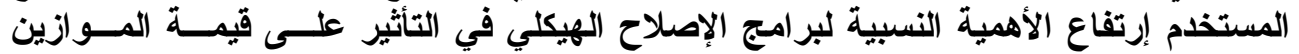

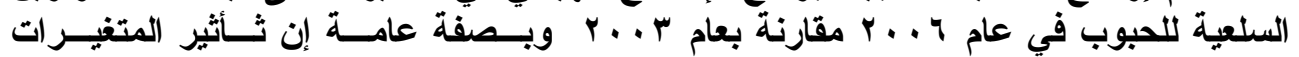

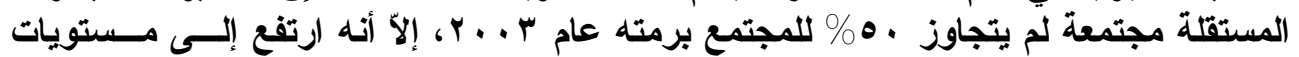

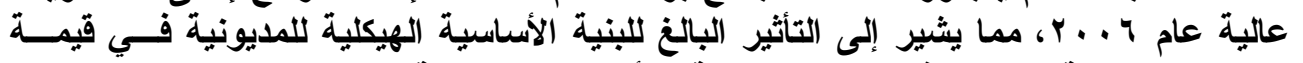

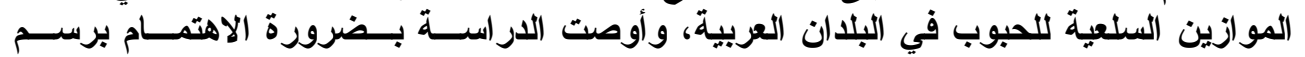

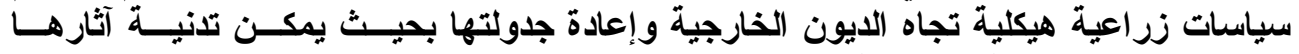

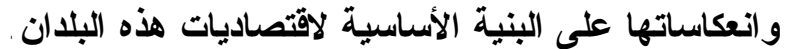

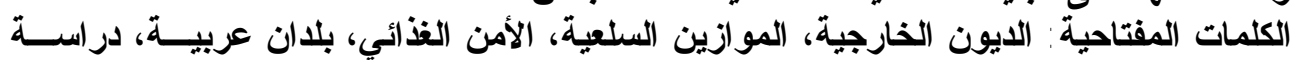

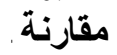

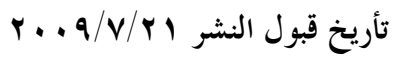

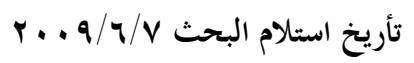




\title{
The Impact of External Debts in Value Good Balances of Cereals in Some Selected Arab Countries: A Comparative Study
}

\author{
Amina A. Al-Hasson \\ Assistant lecturer \\ Department of agricultural Economics \\ University of Mousl
}

\begin{abstract}
External debts are considered one of the most important issues faced by Arab countries in the passed decades, as they are an obstacle against achieving development. They began in fifties on an international level and their features became clearer in nineties when the amount of debts aggravated as a result of malfunctioning them. It was clear that there was internal and external causes that contributed in increasing the burdens of debts including the deficit in the general balance and the deterioration in the terms of commercial exchange. It was obvious from the model used that there is an increase in the relative importance of the structural reform programs in affecting the value of the good balances of cereals in (2006) in comparison with the year (2003). In general, the influence of the whole independent variables did not exceed (50\%) for the whole population in (2003). But, it increased to high international levels in (2006), indicating the great influence of the basic structure of debts on the value of good balances of cereals in Arab countries. The study recommends that there is a necessity to plan structural agriculture policies concerning the external debts and rescheduling them in a way that minimizes their impacts and reflections on the basic structure of these countries economies.
\end{abstract}

Key words: External debts, good balances.

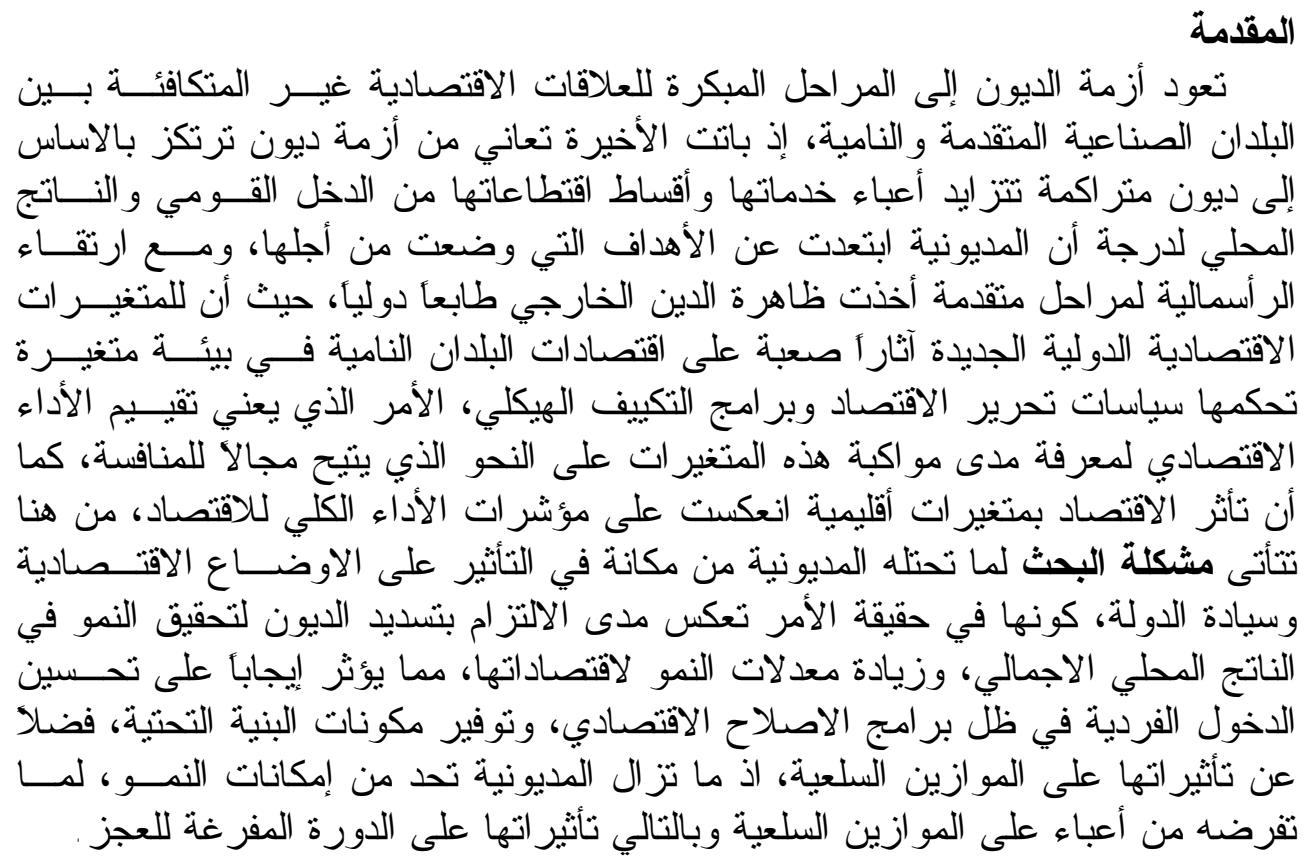


وجاءت أهمية البحث من ضرورة التعرف على أسباب الديون بالنظر إلى أعبائهــا.

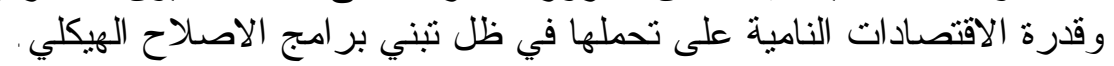

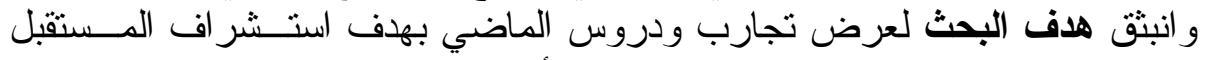

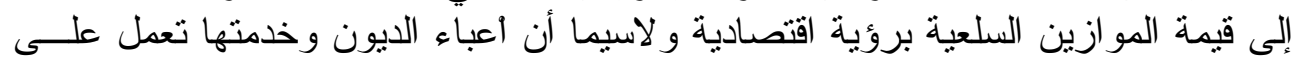

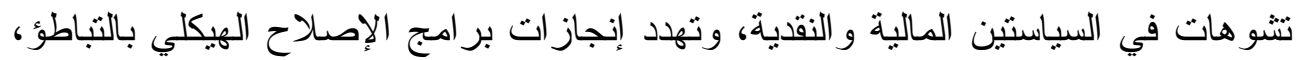

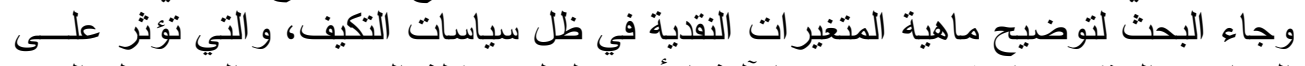

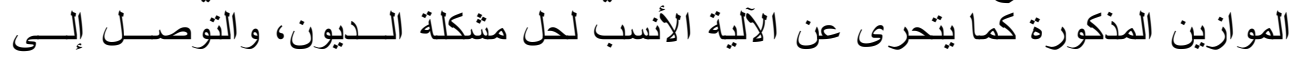

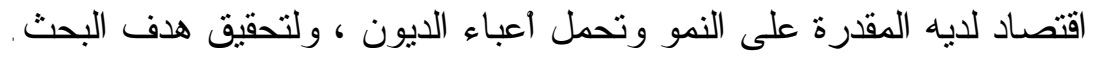

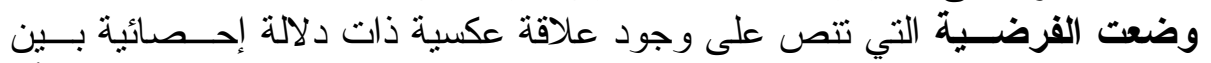

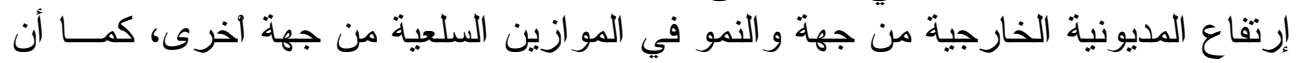

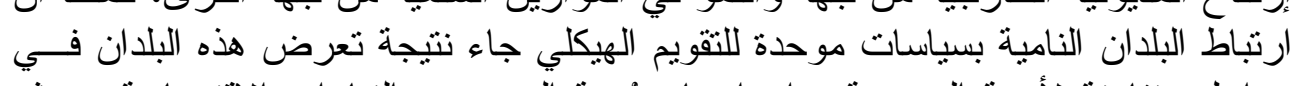

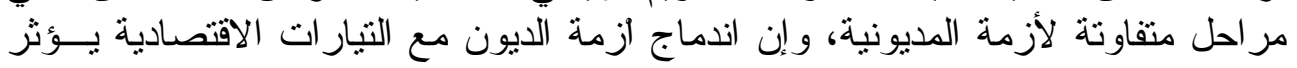
سلبا في معيشة المواطنين، مما قد يؤدي إلى تفاقم الديون وانعدام الأمن الغذائي.

1ـ العرض المرجعي و الاراسات المعاصرة

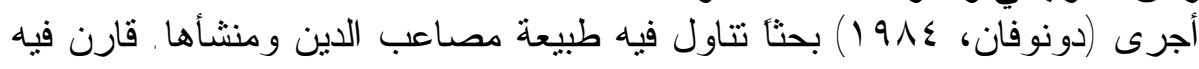

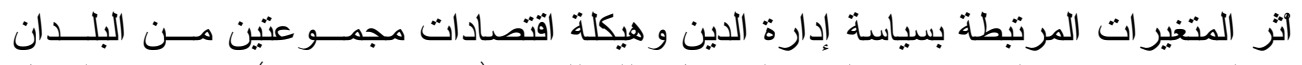

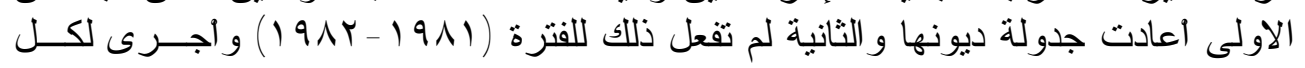

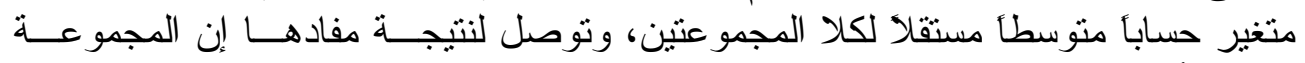

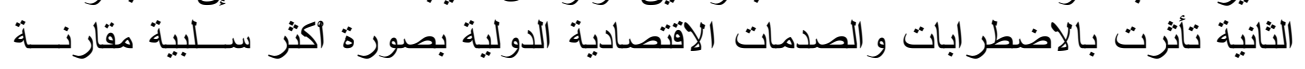

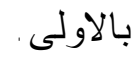

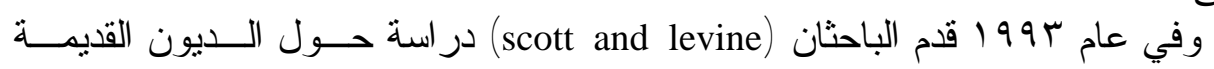

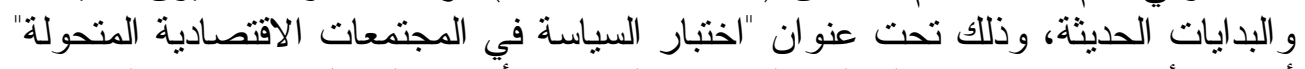

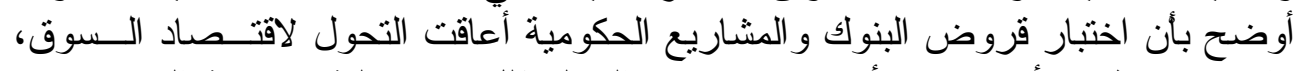

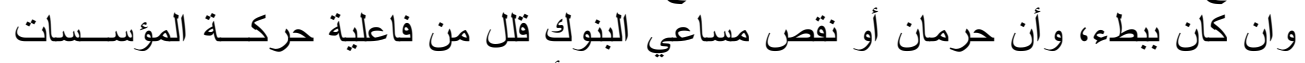

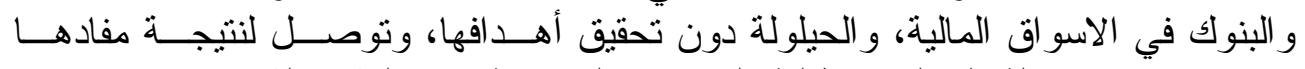

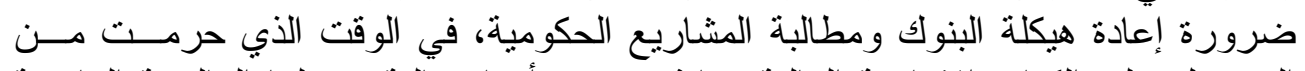

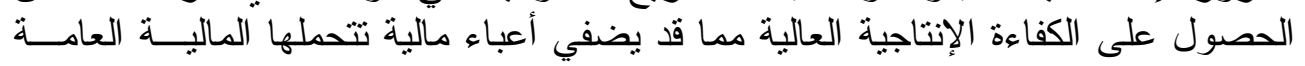
للاولة.

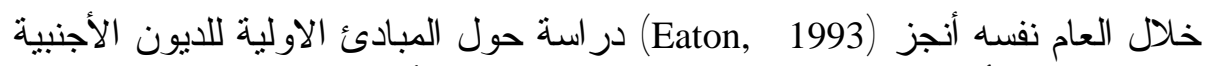

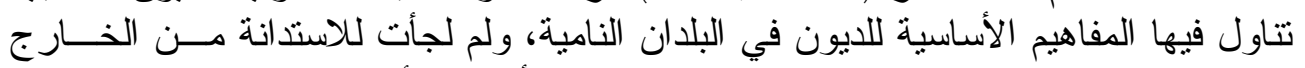

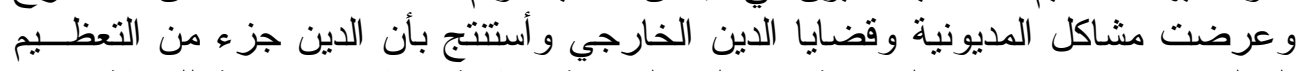

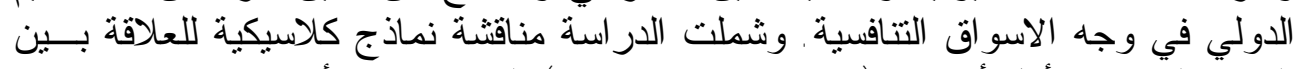

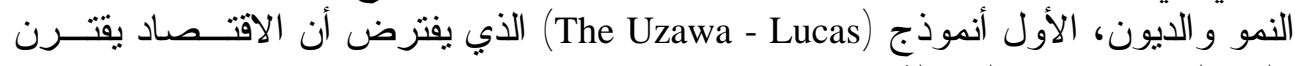
$\mathrm{Q}_{\mathrm{t}}=\mathrm{K}_{\mathrm{t}}^{\mathrm{B}}\left(\mathrm{e}_{\mathrm{t}} \mathrm{N}_{\mathrm{t}}\right)^{1 \mathrm{~B}} \mathrm{H}_{\mathrm{t}}{ }^{1} \mathrm{~B}+\mathrm{y}$

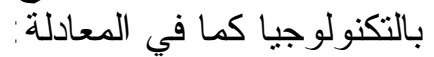




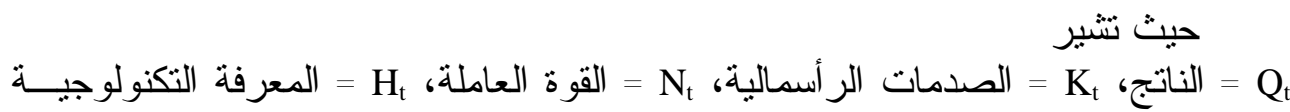

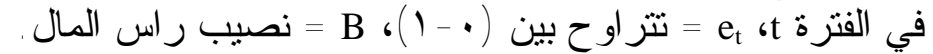
وآلاخر أنموذج (The Cobenm) يبين بأن الصدمات المالية نوضح طبقأ للمعادلة المالة $\mathrm{K}_{\mathrm{t}}=(1-\delta) \mathrm{K}_{\mathrm{t}}-1=\mathrm{I}_{\mathrm{t}}$

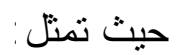

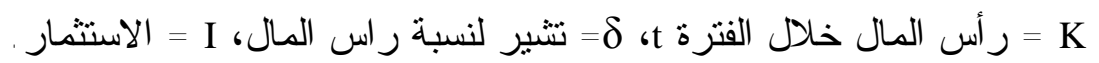

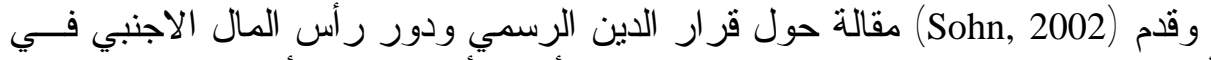

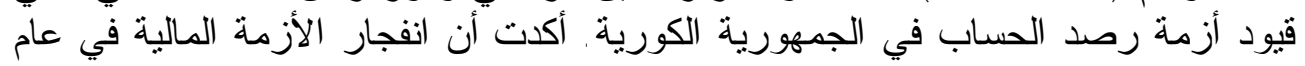

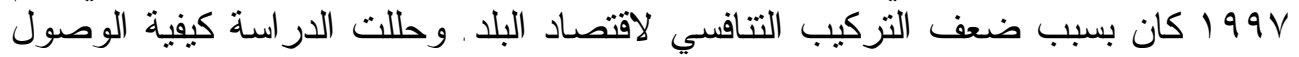

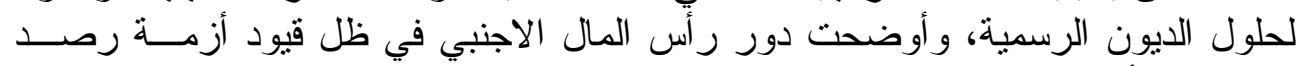

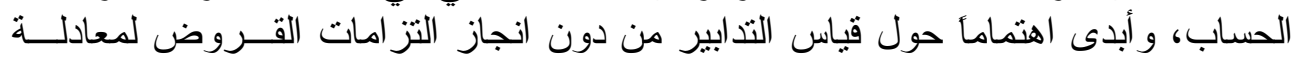

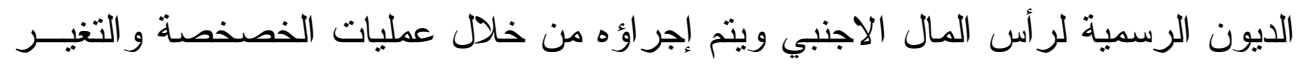

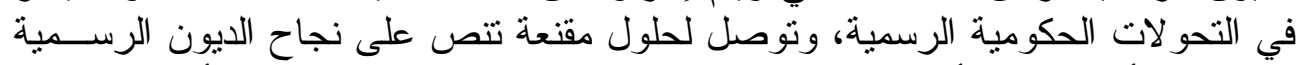

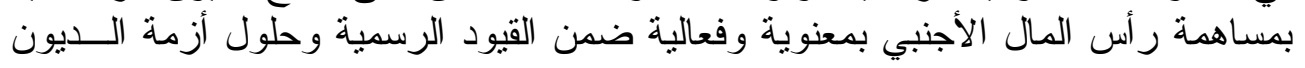

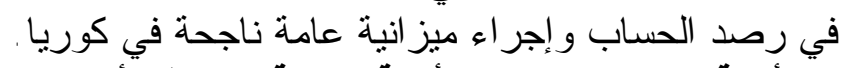

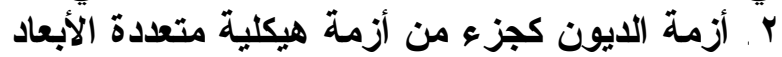

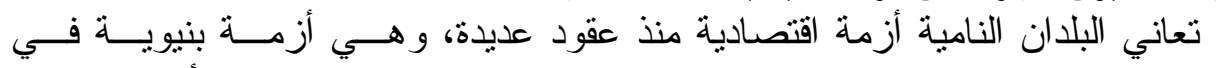

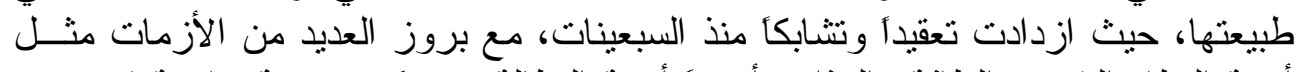

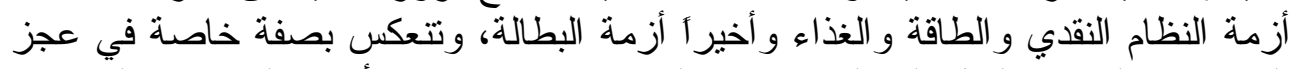

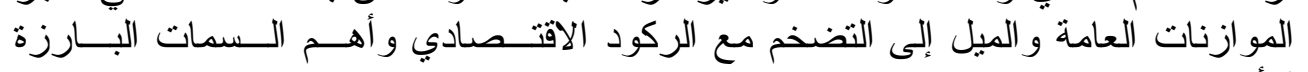
لأزمات هي: الكونات العادة

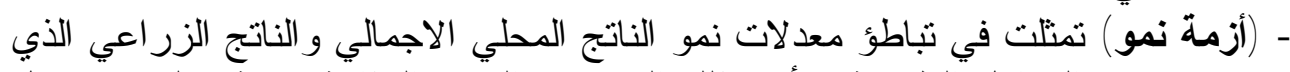

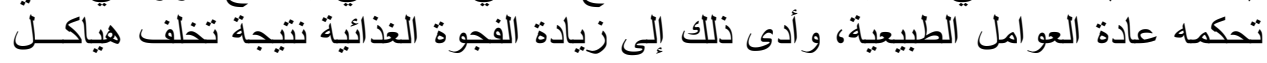

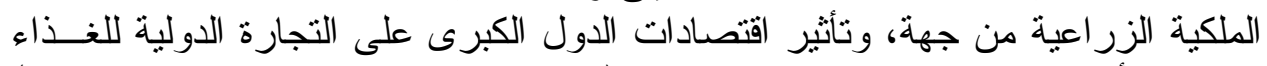

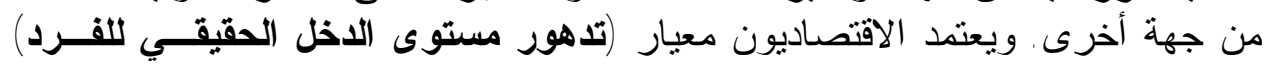

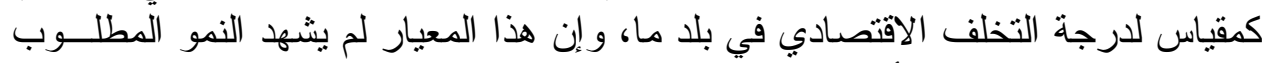

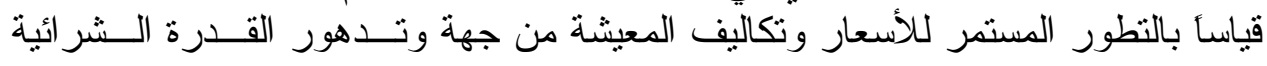

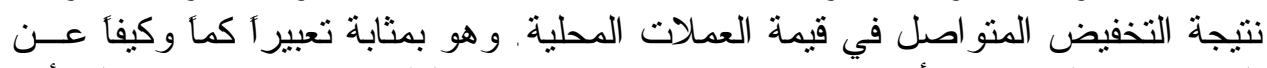

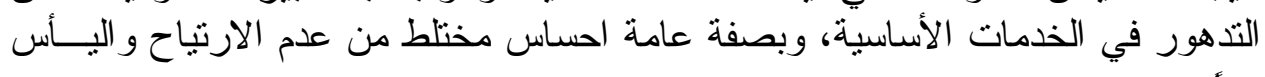

- أزمة تضخم) لقد أصبح التضخم المعتدل أو المنخفض سياسة مقصودة، وينصـح بهـــا

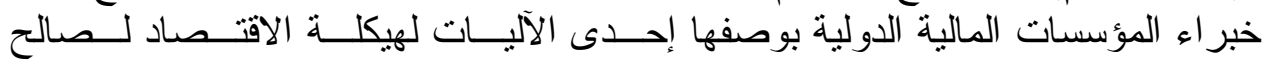

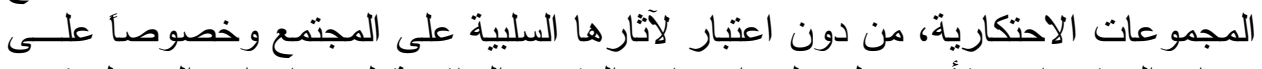

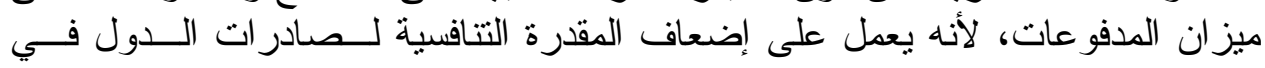

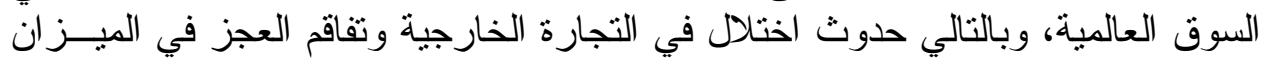

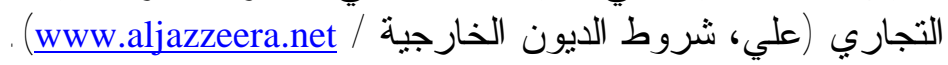




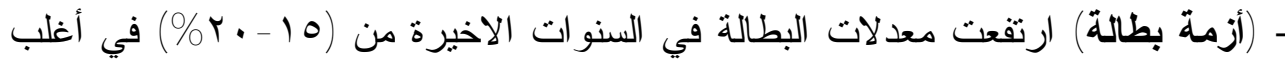

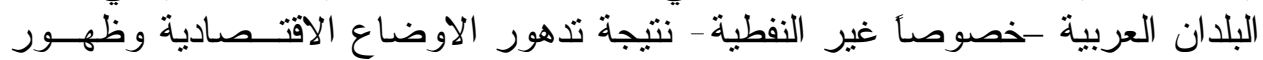

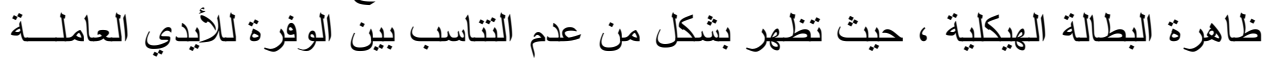
مقابل ندرة العو امل الاقتصادية الإنتاجية الاخرى.

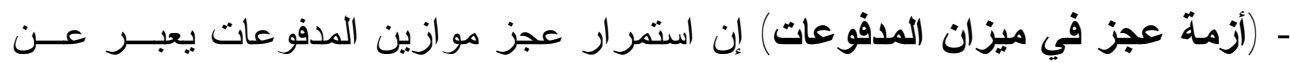

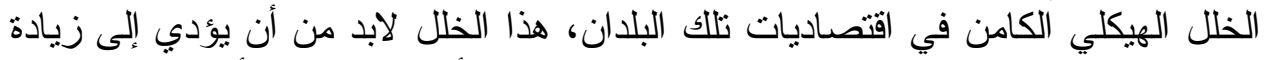

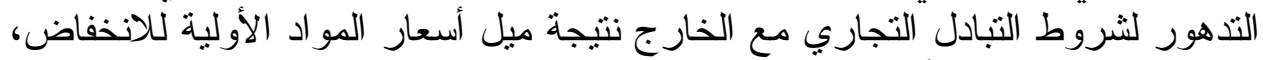

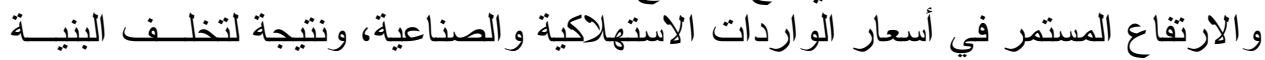

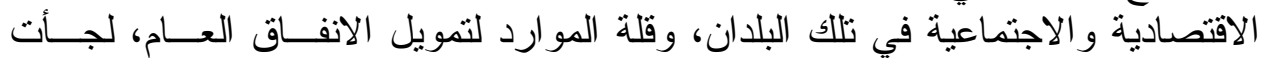
للاستدانة للاسر اع بالتتمية وتغطية العجز في ميز اندان المدفوعات.

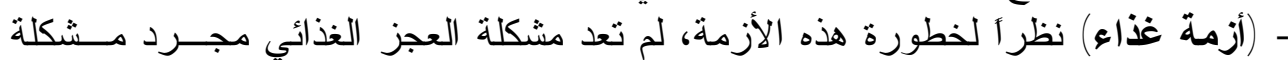

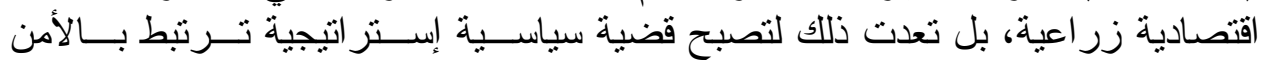

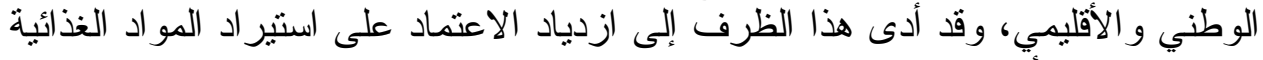

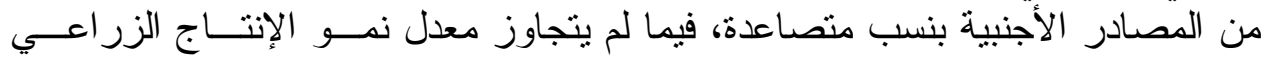

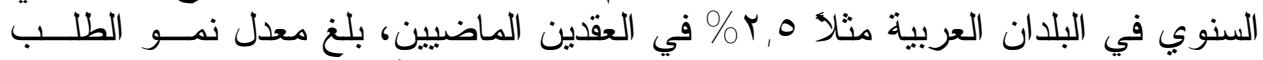

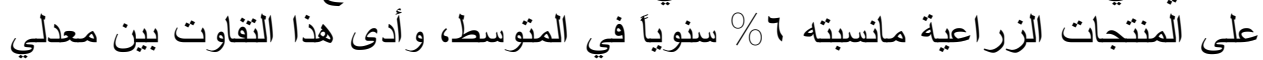

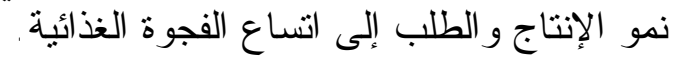

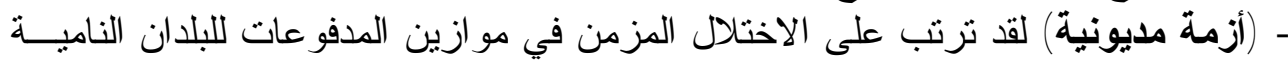

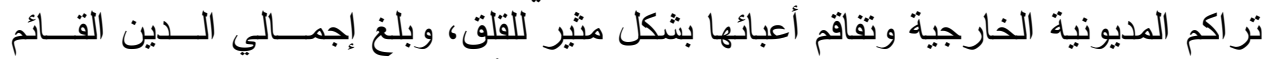

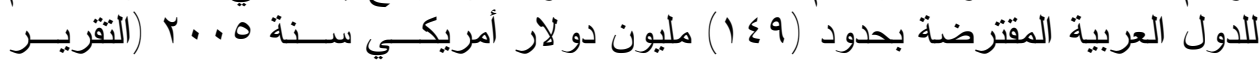

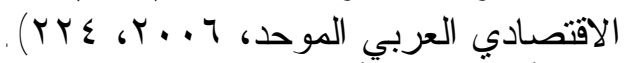

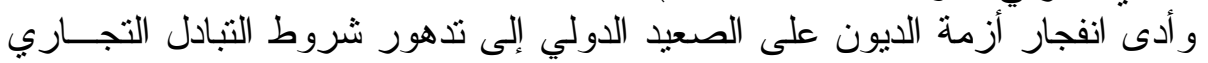

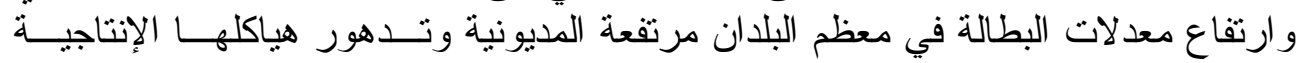
و الهيكلية (علي، wعw.aljazzera.net/NR) .

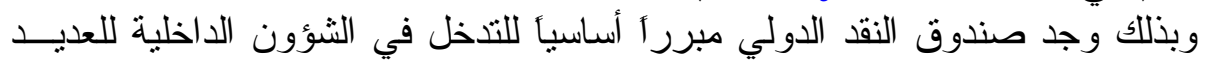

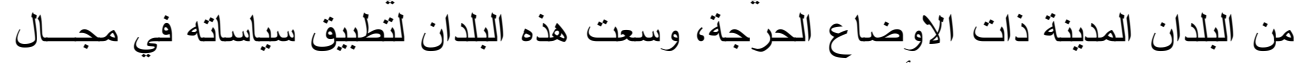

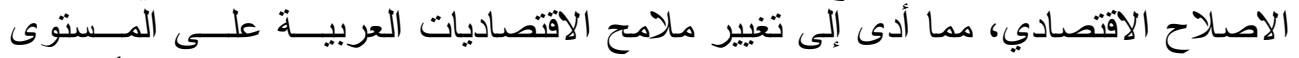

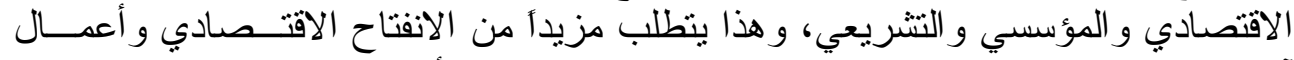

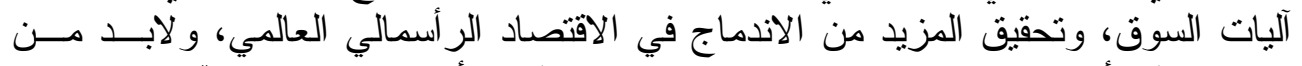

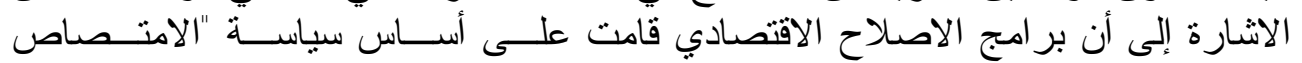

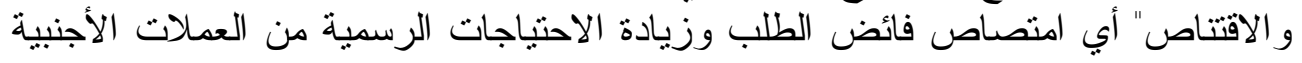

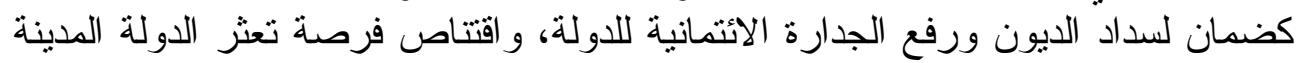

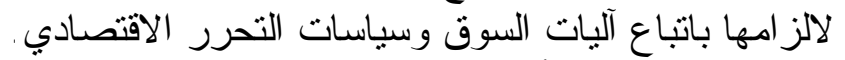

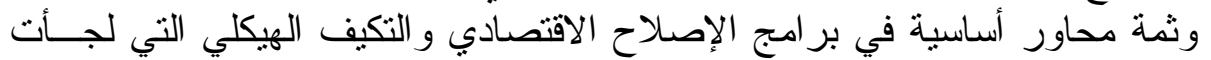

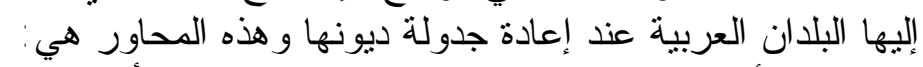

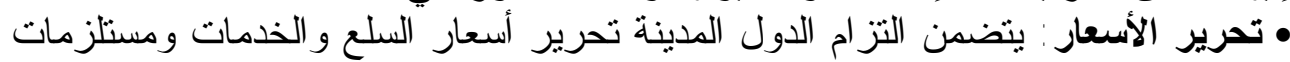

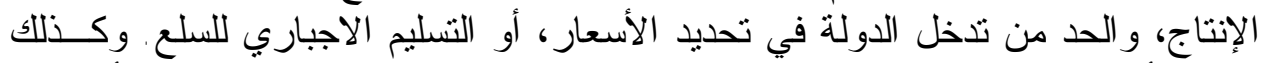

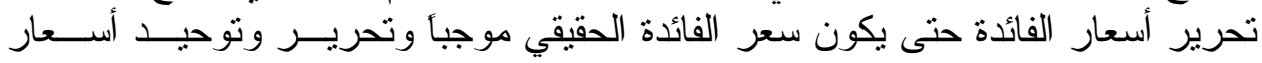


الصرف، وكذللك إلغاء وجود حد أدنى للأجور مما يؤدي لارتفاع الأسعار و الإضـــرار

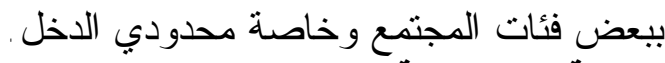

• سياسة الخصخصة: وهو المحور الذي يسعى إلى زيادة دور القطاع الخاص في النشاط

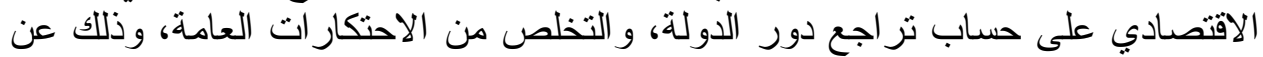

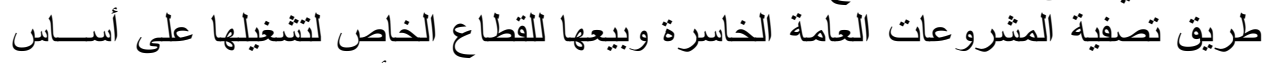

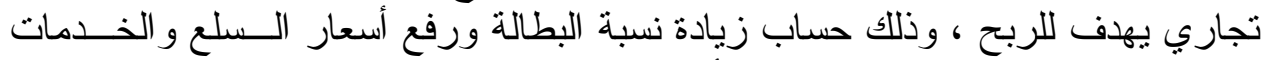

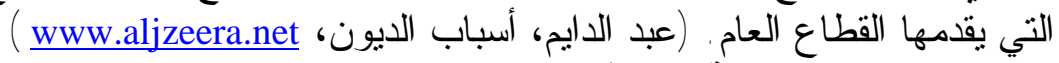

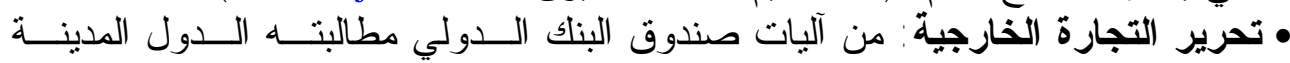

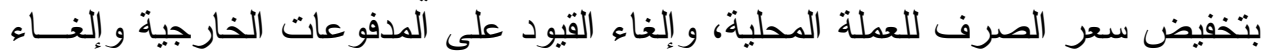

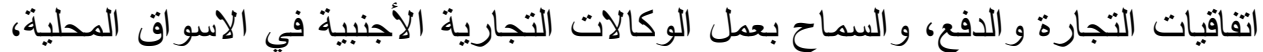

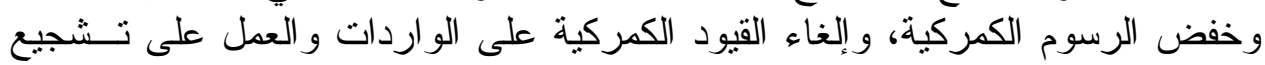

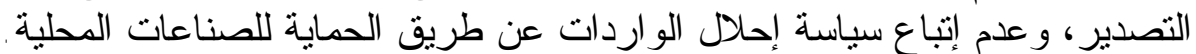

r. إستراتيجية التكيف مع الديّن (إستراتيجية الديّين)

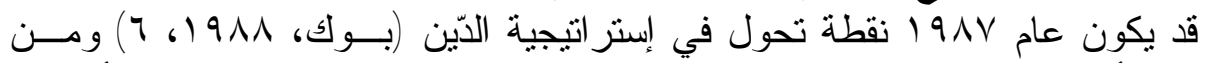

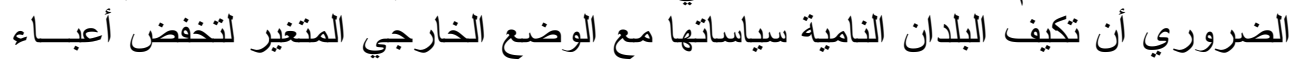

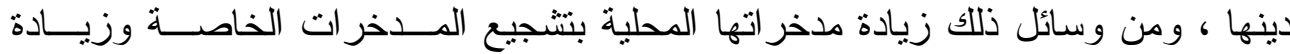

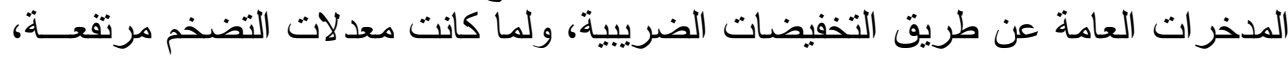

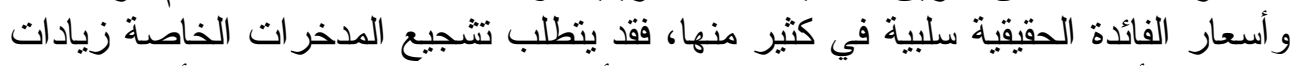

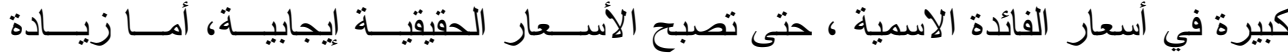

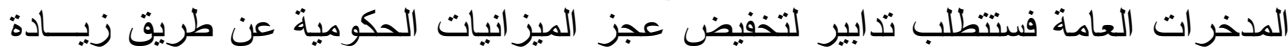

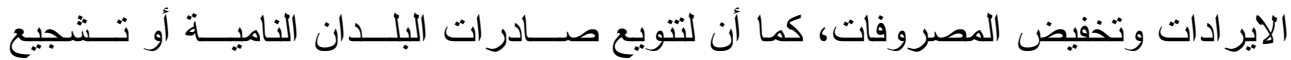

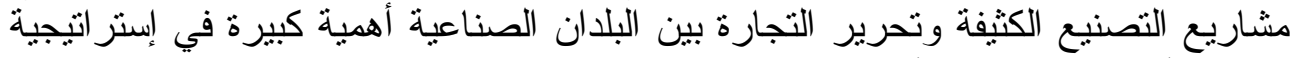

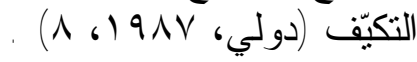

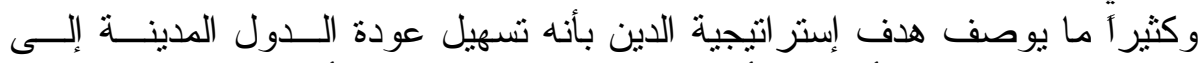

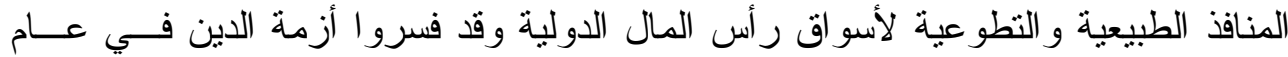

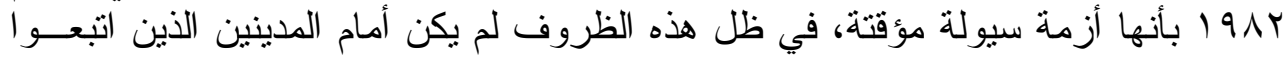

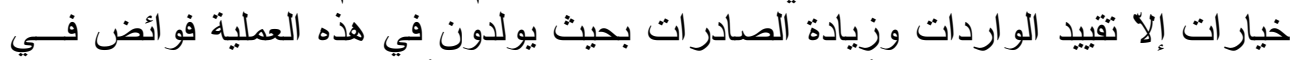

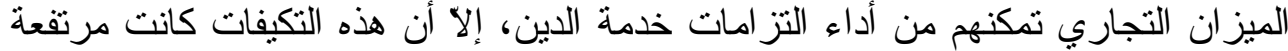

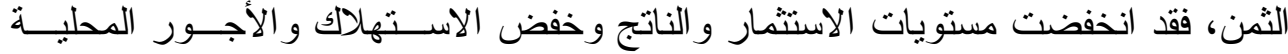

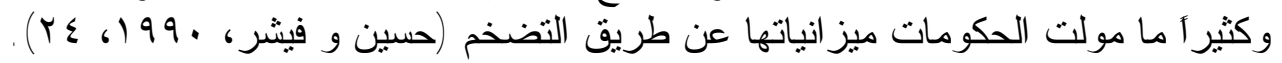

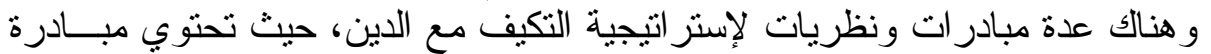

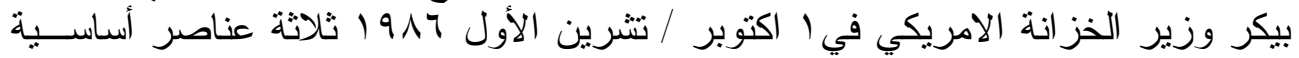
تتساند فيما بينها بشكل طبيعي هي: الاميكي في التيان

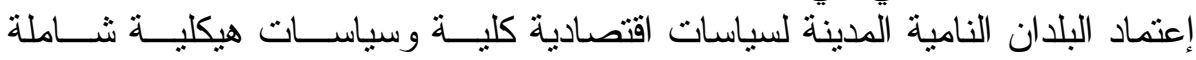

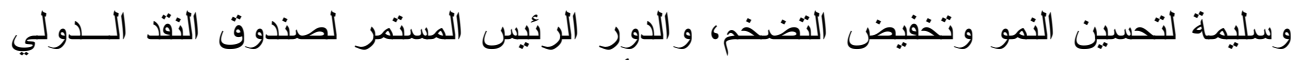

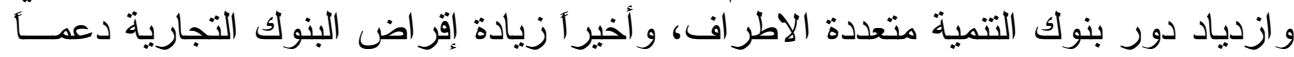

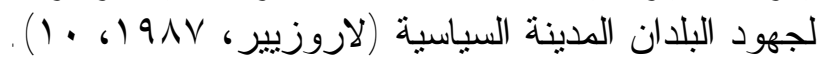


أما نظرية (ننتظكر - ونرّ) فئفسر هذه الإستر اتيجية بأن البلدان النامية ســتخرج

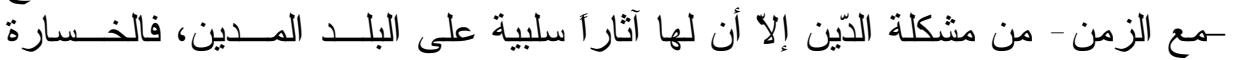

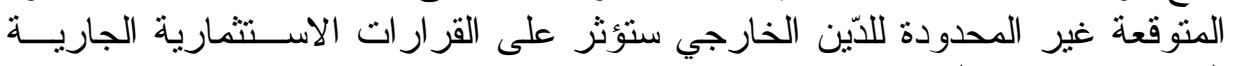

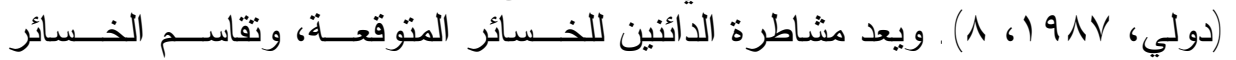

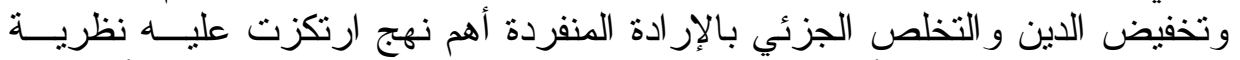

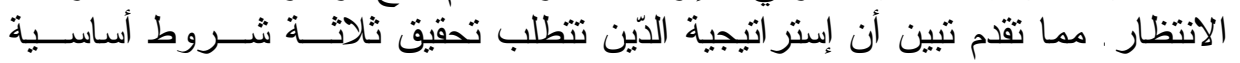
(الحمداني، المديونية الخارجية للبلدان النامية / www.rezgar.com) • تخطيط الموارد و استخداماتها. • ت نوفير الحماية للصناعات المحلية.

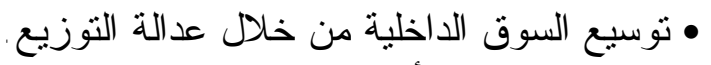

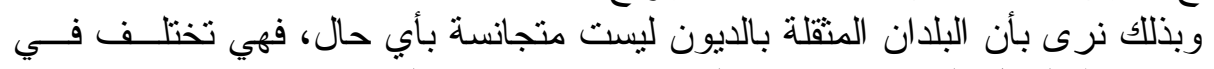

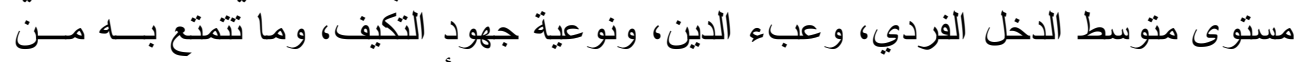

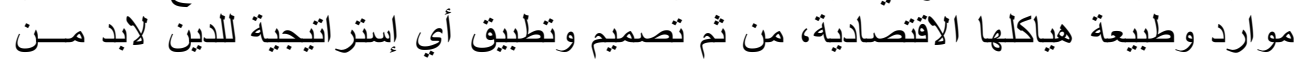

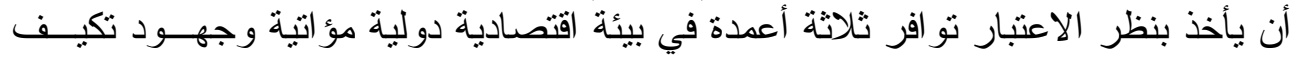

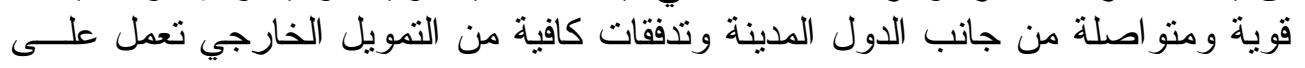

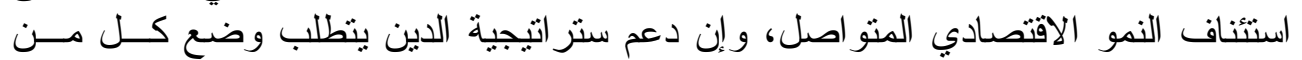
جهود التكيف ومجمو عات التمويل المرتبطة في إطار منوسط الاجل.

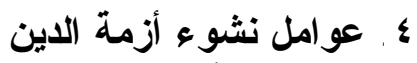

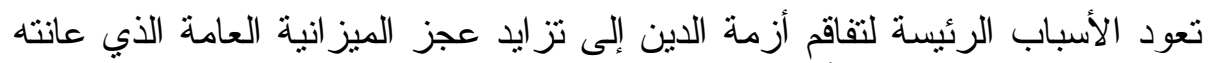

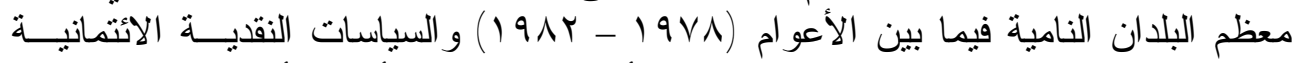

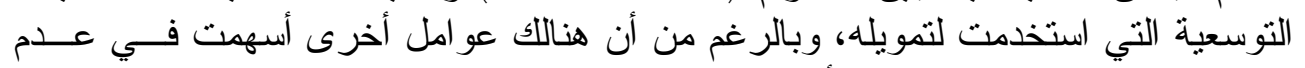

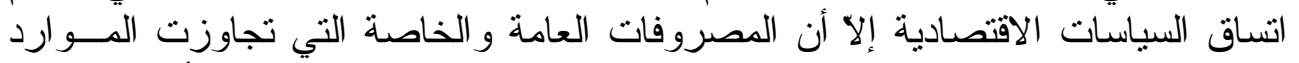

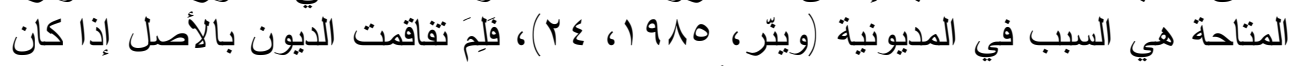

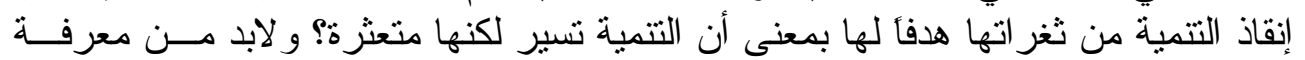

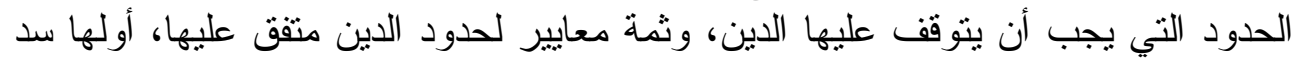

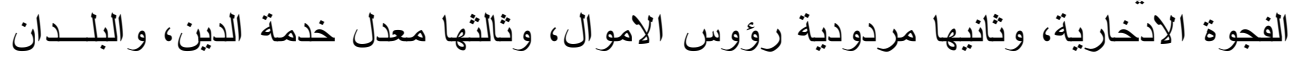

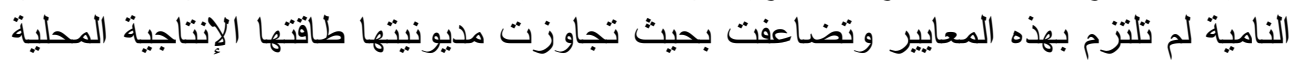

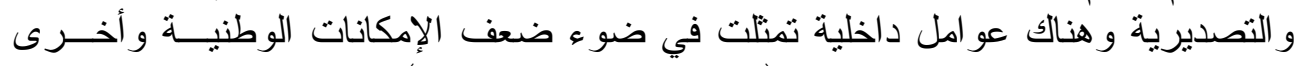

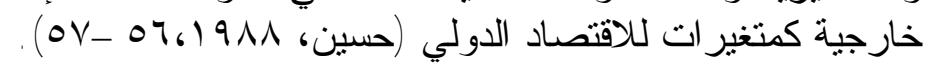

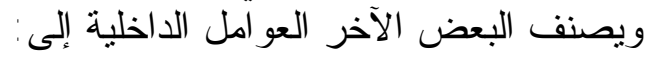

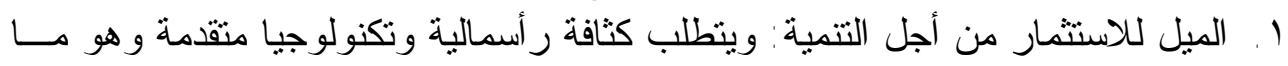

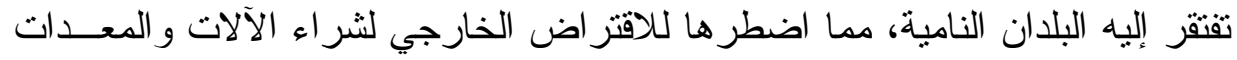

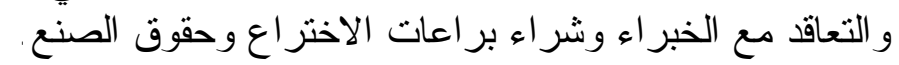

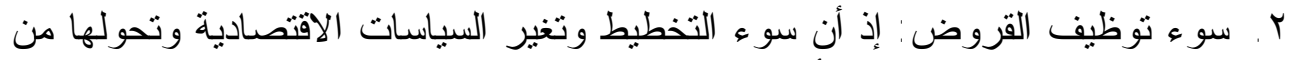

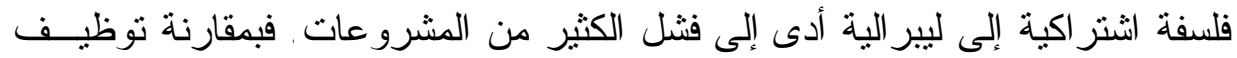

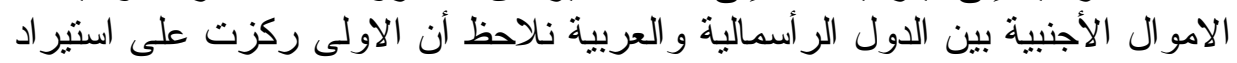

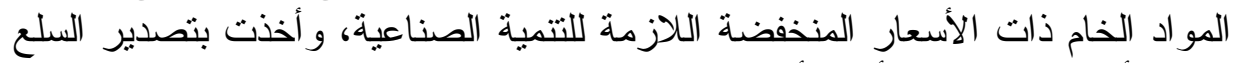
ذات الأسعار المرتفعة، أما الأخرى فقد ركزت على اســتيراد الـــلع الاســتهلاكية 


\section{الحسون[1}

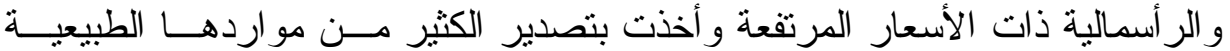

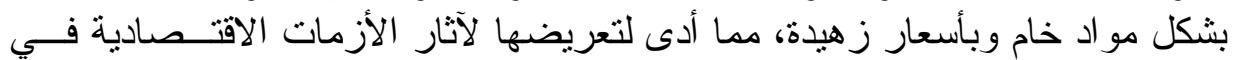

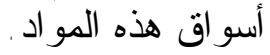

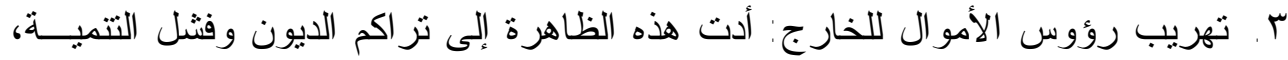

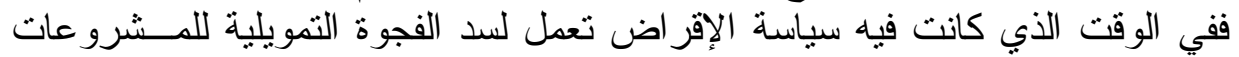

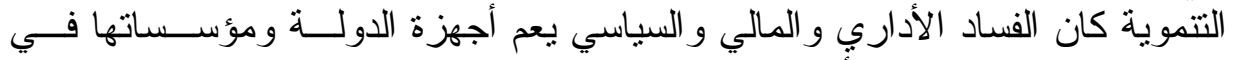

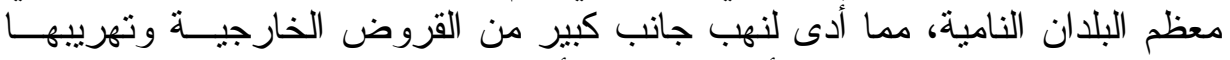

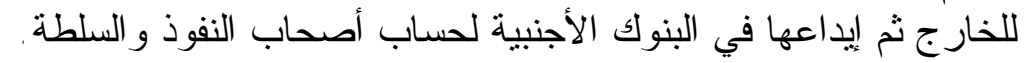

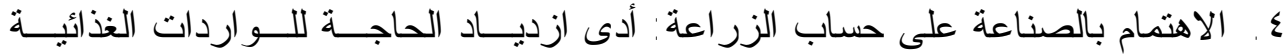

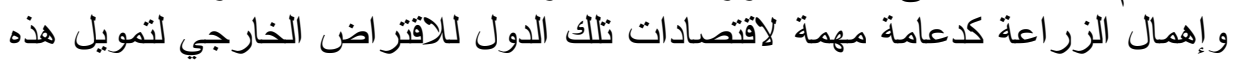

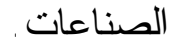

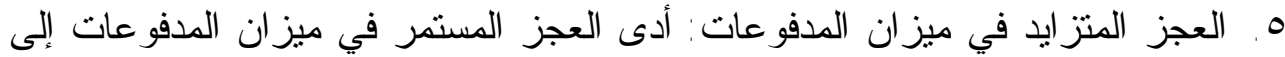

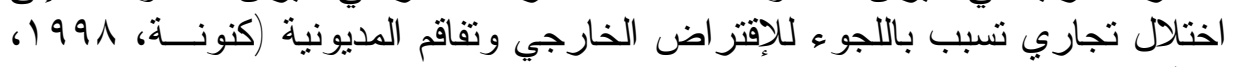

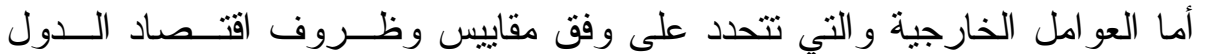

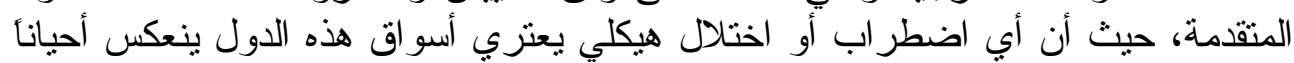

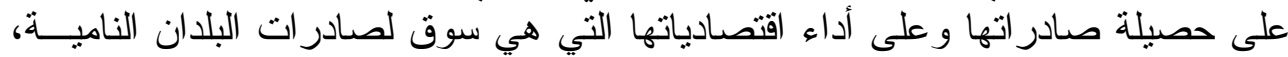

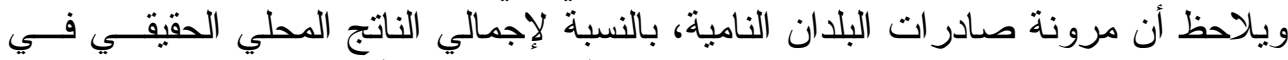

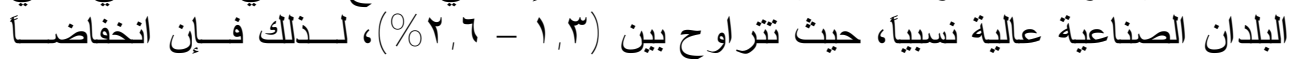

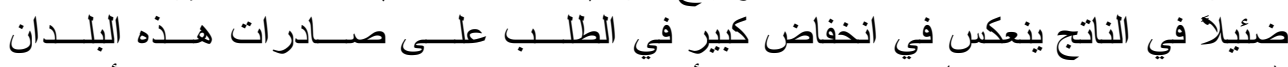

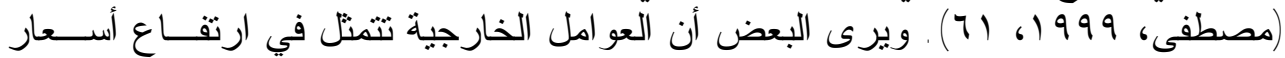

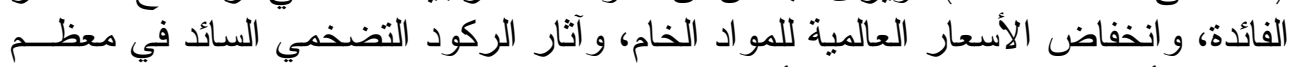

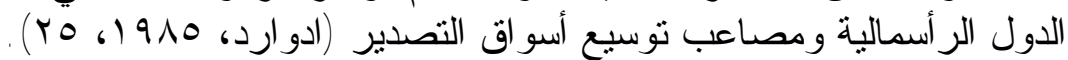

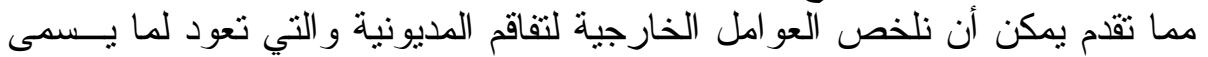

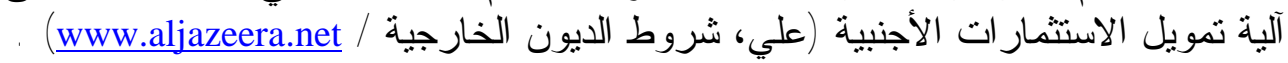




\section{$[1 \leqslant r]$}

اثر المديونية الخارجية في قيمة الموازين السلعية...

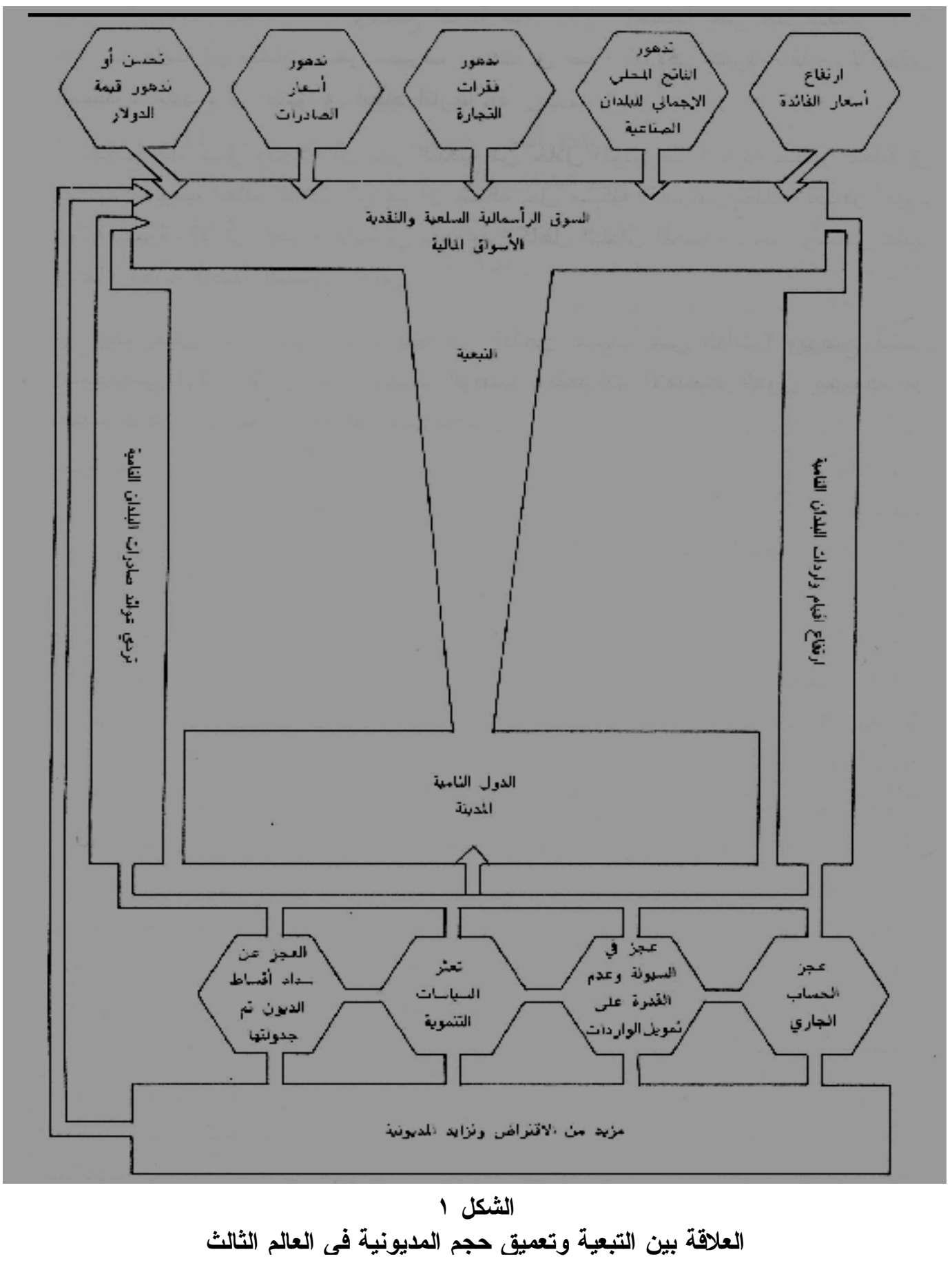

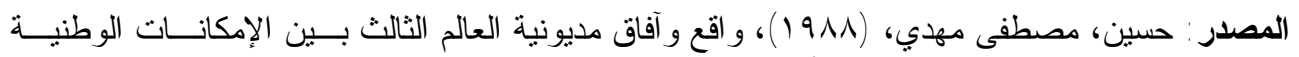
ومتغيرات الاقتصاد الدولي، آفاق اقتصادية، العدد بـا، السنة التاسعة. 


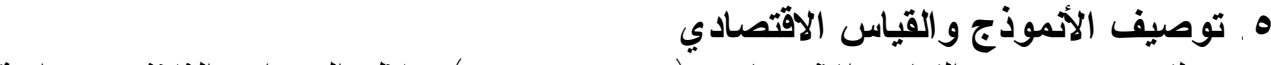

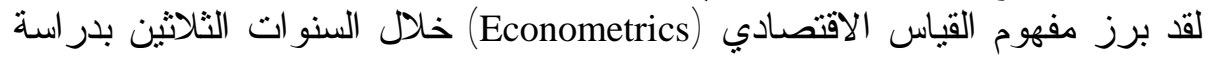

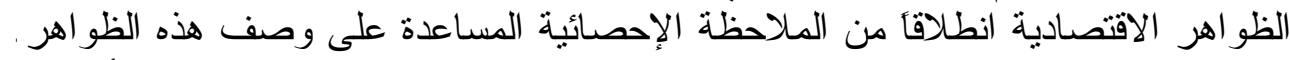

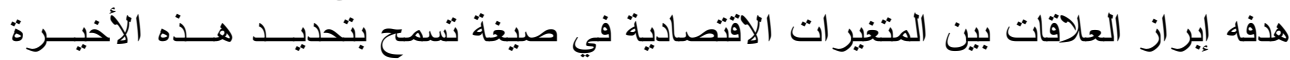

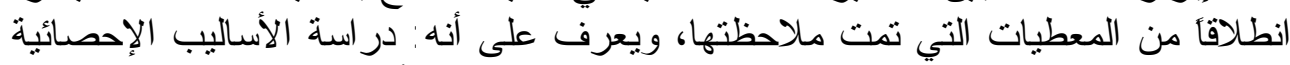

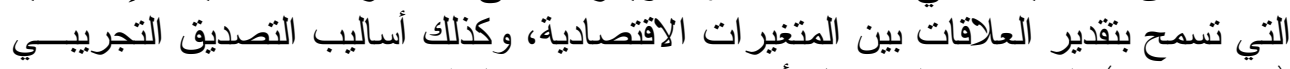
(Validation)

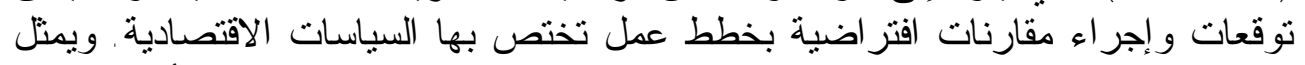

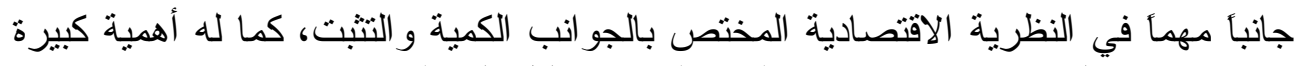

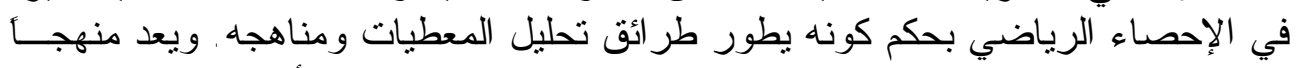

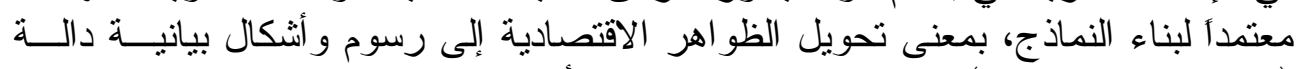
(www.orientation.tn)

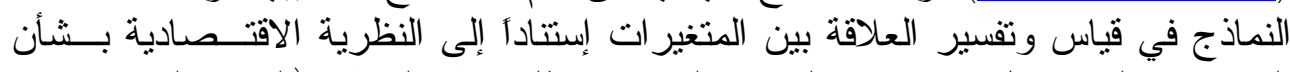

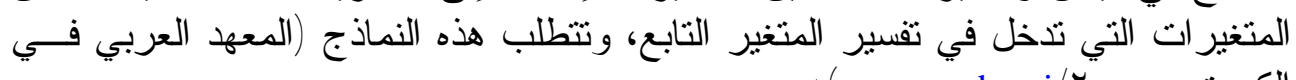

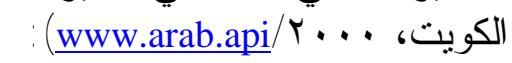

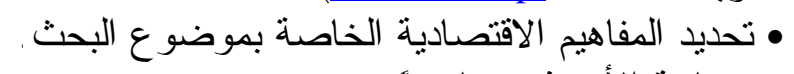

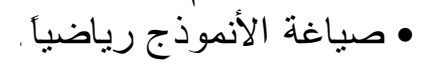

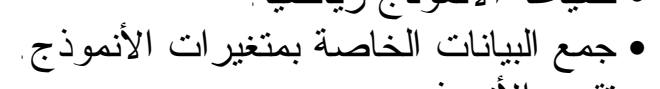

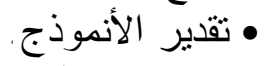

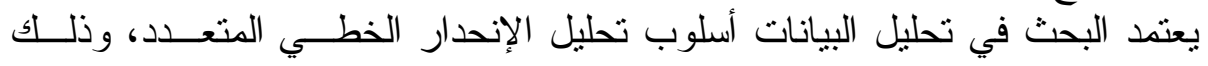

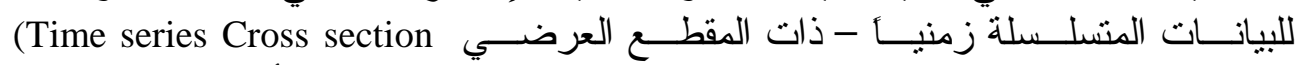
Regression)

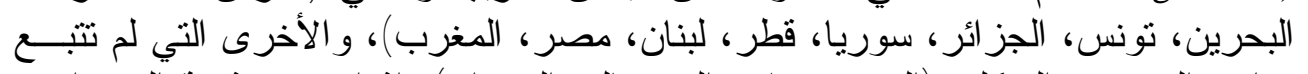

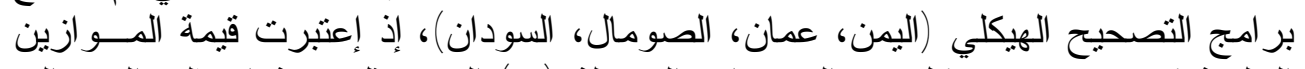

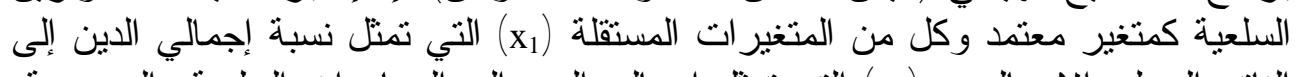

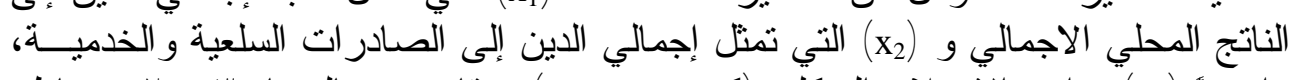

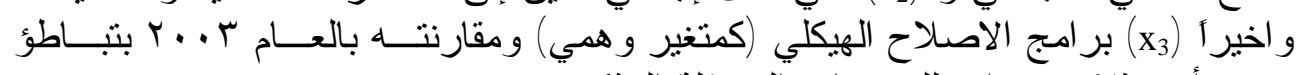

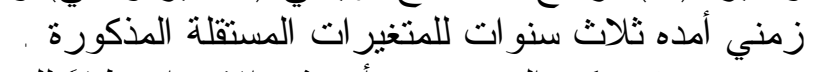

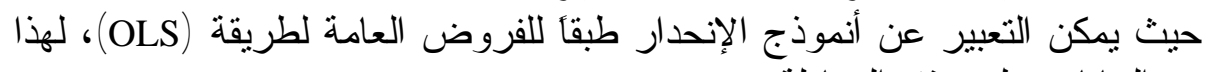
النمط من البيانات على وفق المبير عن أنمادلة: $Y_{i t}=\beta_{1}+\sum_{k=2}^{k} \beta_{k} x_{k i t}+e_{i t}$

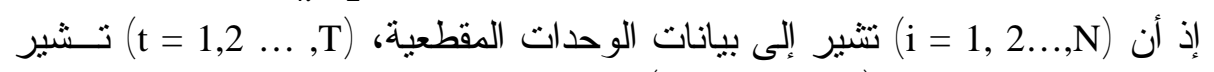

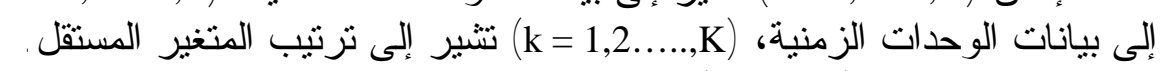

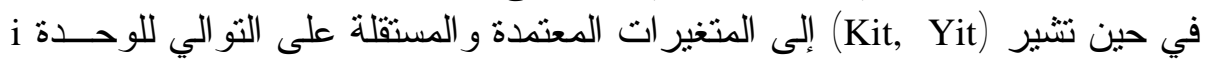

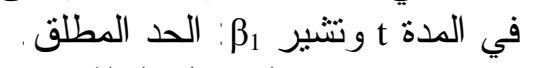

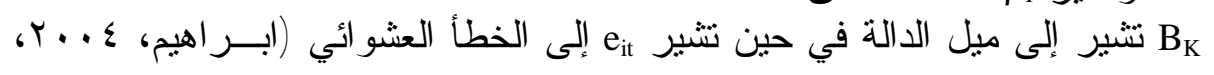




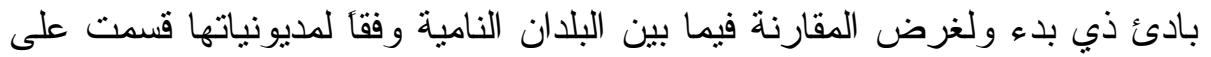

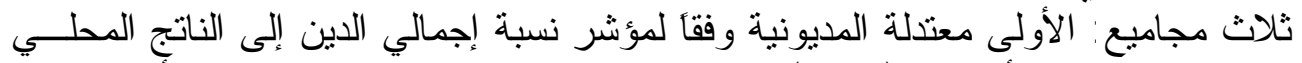

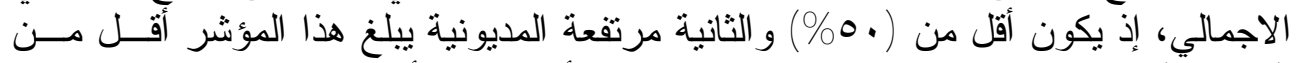

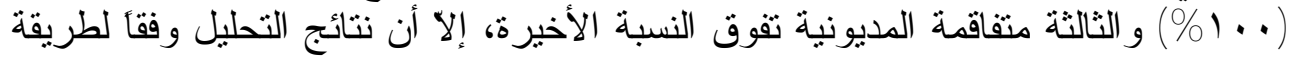

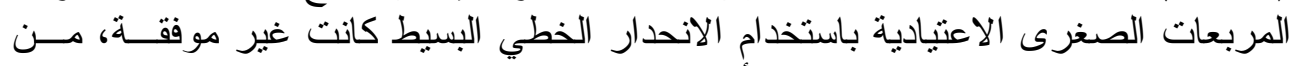

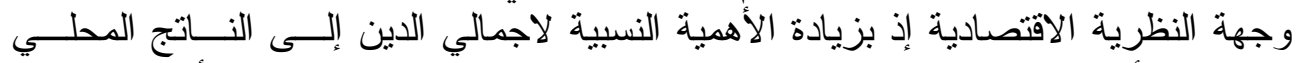

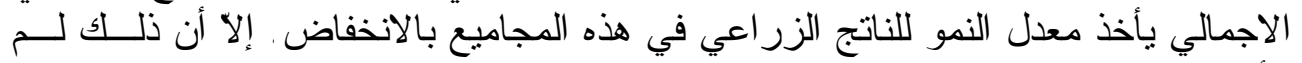

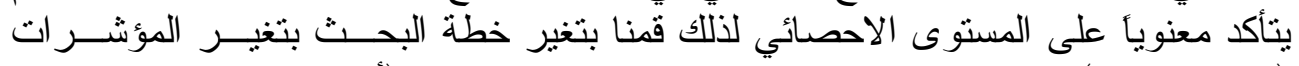

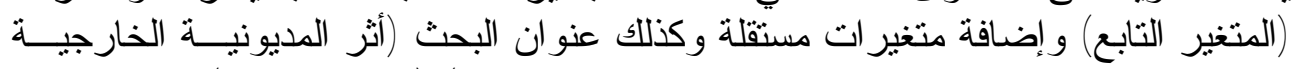

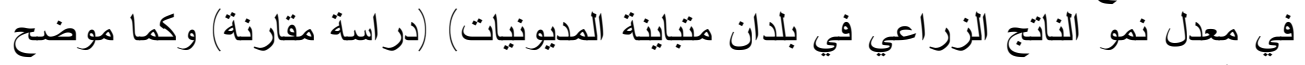

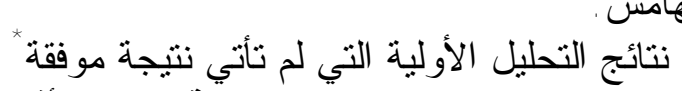

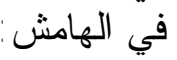

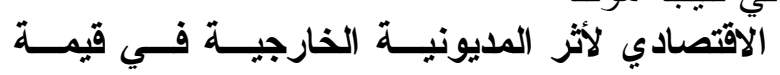

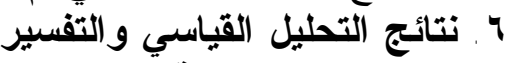
الموازين السلعية للحبوب.

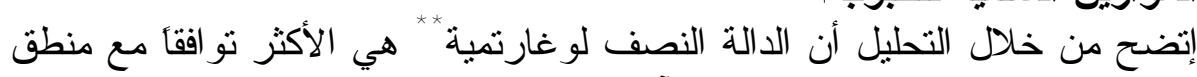
النظرية الاقتصادية وكانت نتائج التحليل كالآتي: $\log \mathrm{Y}_{2006}=1.13+0.0113 \mathrm{X}_{1}-0.00951 \mathrm{X}_{2}+0.105 \mathrm{X}_{3}$

$$
\begin{aligned}
& \mathrm{t} \quad(34.20)(12.13) \quad(-4.08) \\
& \mathrm{R}^{2}=97.4 \% \quad \mathrm{R}^{\prime 2}=96.3 \% \\
& \mathrm{~F}=82.85 \quad \text { D.W }=1.33
\end{aligned}
$$

$\log \mathrm{Y}_{2006}=2.53-0.0072 \underset{\mathrm{t}-3}{\mathrm{X}-3}-\underset{\mathrm{t}-3}{0.0043 \mathrm{X}_{2}}+\underset{\mathrm{t}-3}{0.375} \mathrm{X}_{3}$

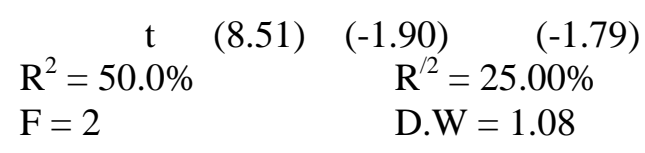

- $\mathrm{Y}_{1}=6.69-0.102 \mathrm{X}_{1}$

(3.09) (-1.49)
$\mathrm{R}^{2}=7.6 \%$

$$
\mathrm{R}^{12}=4.2 \%
$$
$\mathrm{F}=2.22$
D. $\mathrm{W}=1.61$

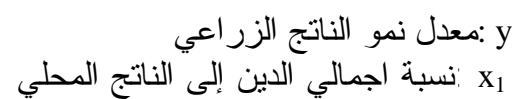

- $\mathrm{Y}_{2}=8.83-0.0594 \mathrm{X}_{2}$

(3.17) (-1.55)

$\mathrm{R}^{2}=11.7 \%$

$\mathrm{F}=2.39$

$\mathrm{R}^{12}=6.8 \%$

- $\mathrm{Y}_{3}=4.29-0.0115 \mathrm{X}_{3}$

$\mathrm{R}^{2}=0.4 \%$

$\mathrm{F}=0.20$

$\mathrm{R}^{12}=0.0 \%$

D.W $=1.84$

$\frac{\beta}{y^{\prime}}=$ * تحتسب المرونة للا الة نصف اللوغارتمية من المعادلة التالية 


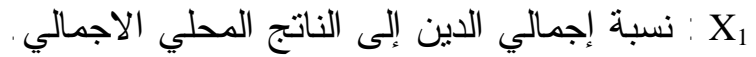

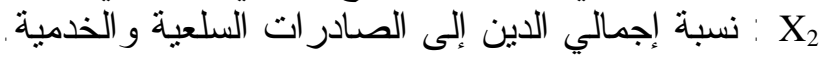

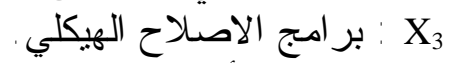

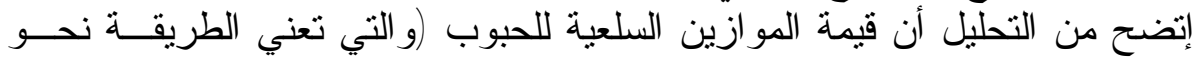

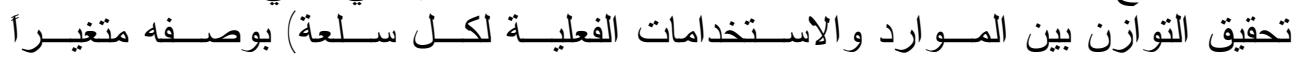

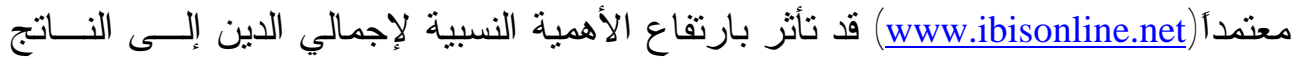

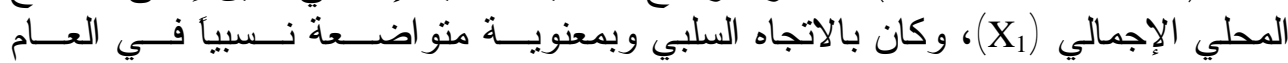

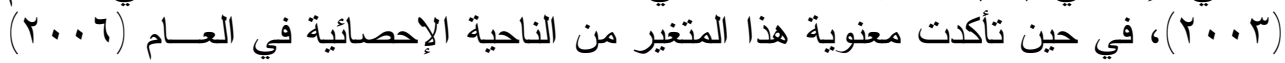

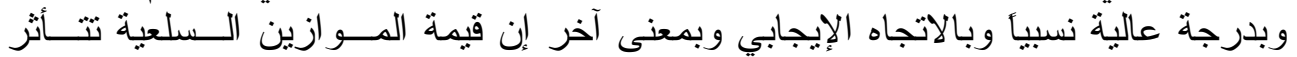

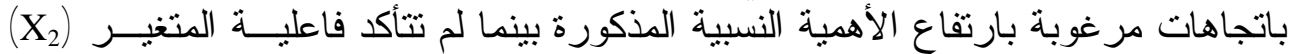

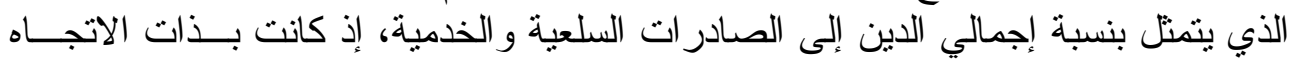

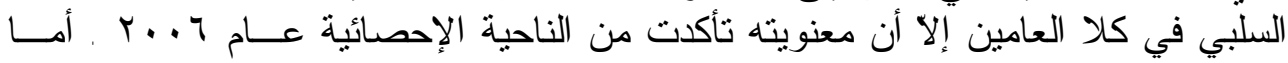
(X3)

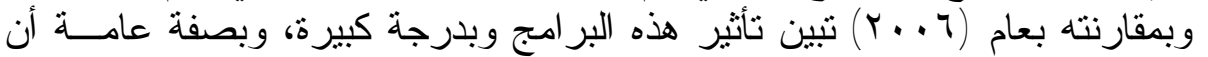

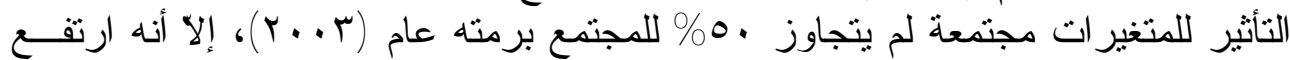

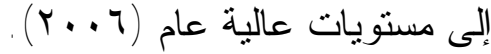

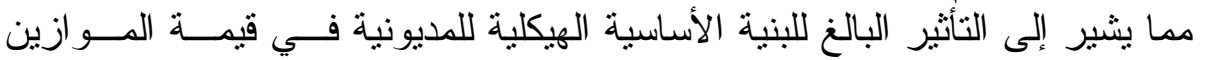

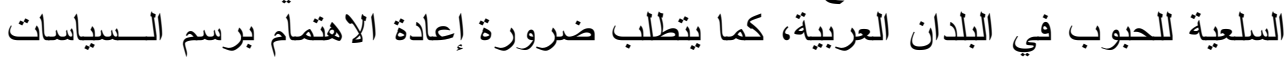

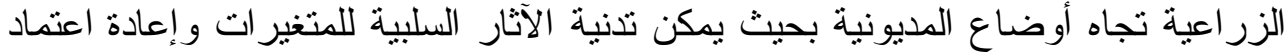

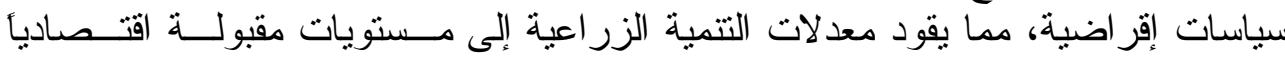

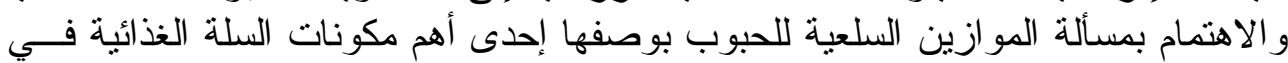

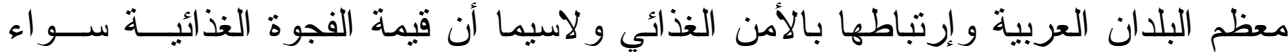
للحبوب أو السلع الأخرى آخذة بالنز ايد.

الاستنتاجات

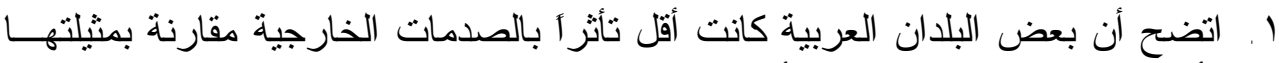

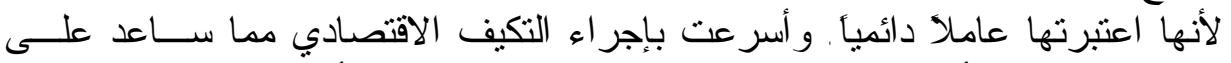

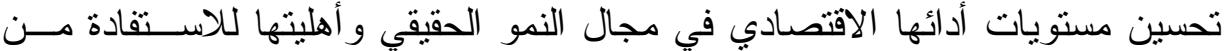

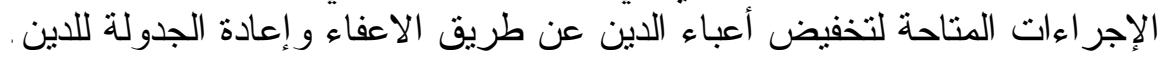

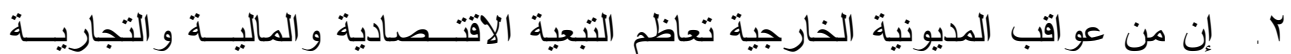

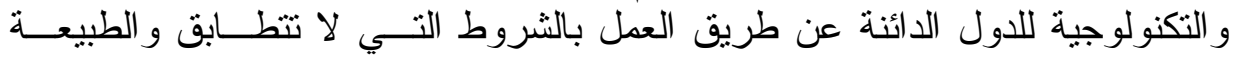

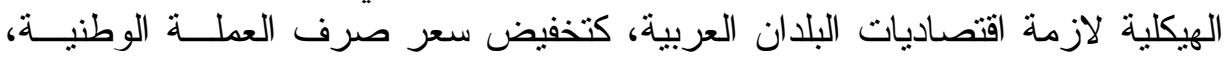

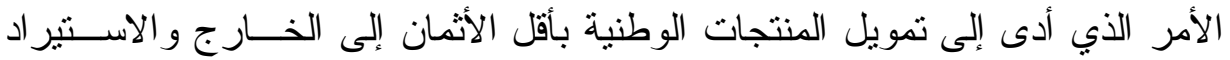
بأعلى تكلفة ممكنة. r. ت تأثير العو امل الخارجية بتفاقم المديونية بنسبة مرتفعة نسبياً كالتجارة الدولية و الحماية الكمركية وسياسات صندوق النقد الدولي مقارنة بالعو امل الداخلية. 


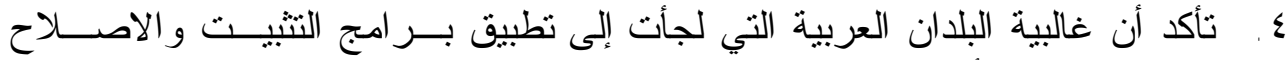

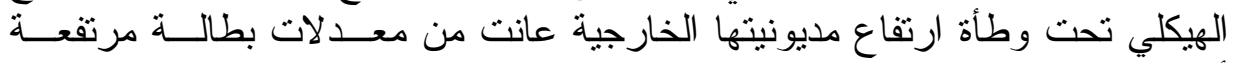
أصبحت تهدد استقر ارها الاقتصادي و السياسي.

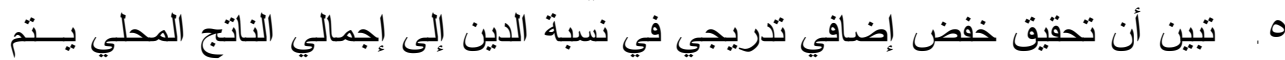
بتوجيه الجز ء الأكبر من أية فو ائض مالية مستقرة في الميز انية العامة.

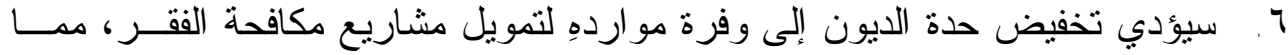

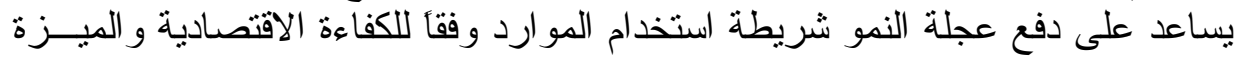
النسبية ودعمها ببر امج شاملة للاصيلاح الهيكلي.

على ضوء الاستتناجات وضعت المقترحات لعلها تدر أ خطر أزمة الديون:

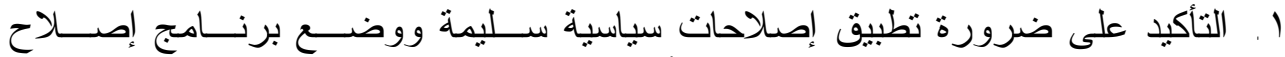

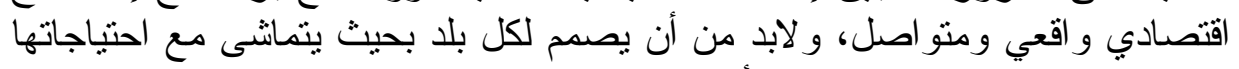

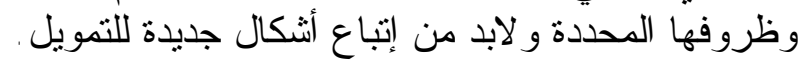

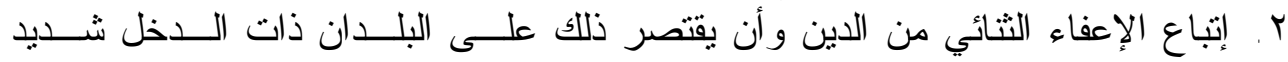

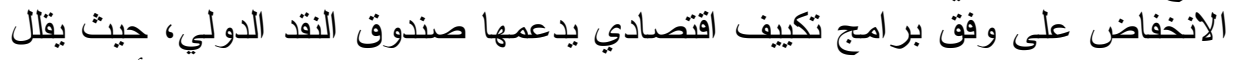

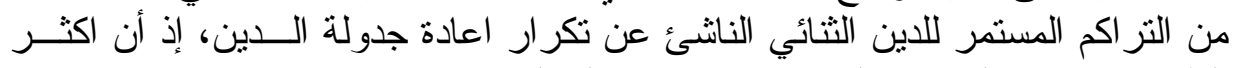

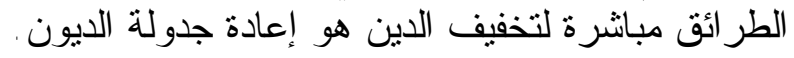

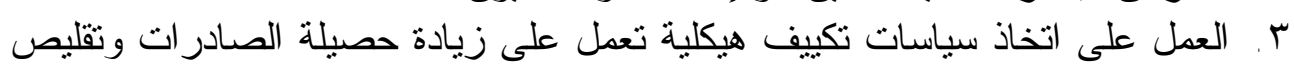

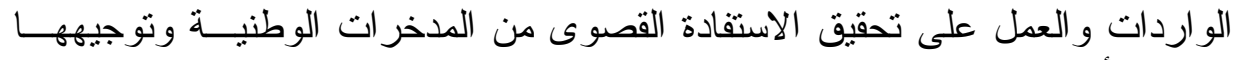

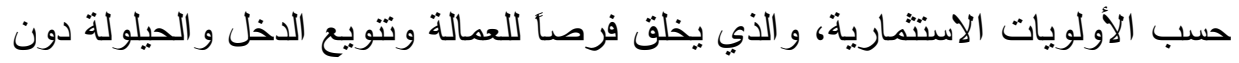

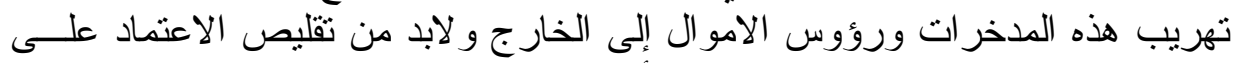

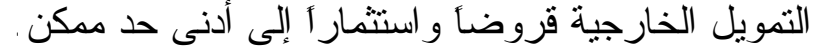

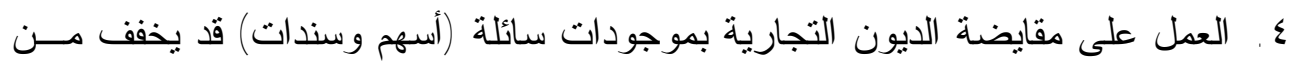

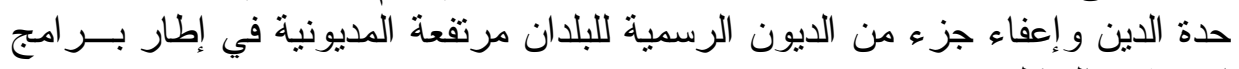
الإصلاح الهيكلي.

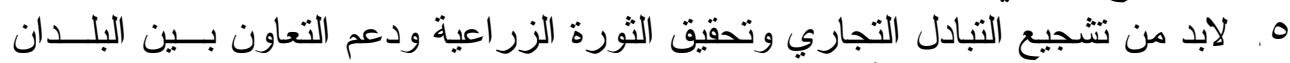

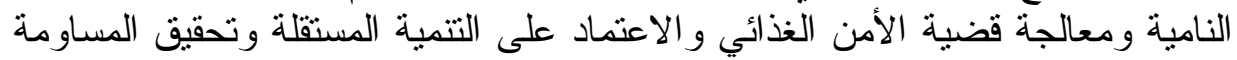

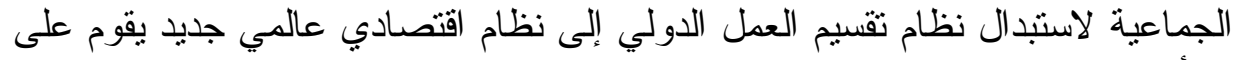

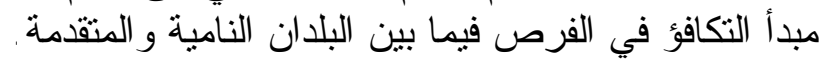

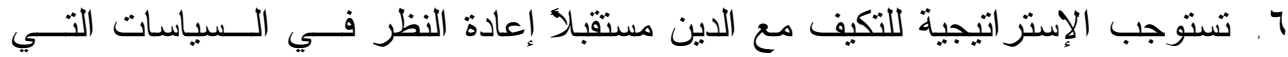

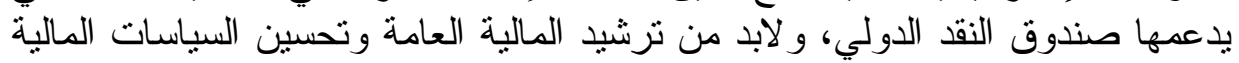

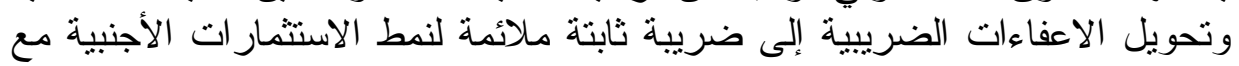
المكاسب الاقتصادية التي تحققها. 
$[1 \leqslant \wedge] ن$

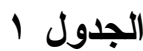

مقارنة بين بلان العينة المتبعة لبرامج الاصلاح الهيكلي للعام († . . ب) بتباطؤ زمني

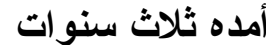

\begin{tabular}{|c|c|c|c|c|c|c|c|}
\hline تيزيران & السلوازيلين & 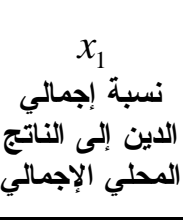 & 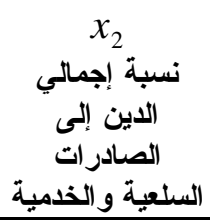 & 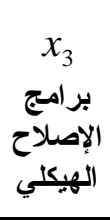 & $x_{1_{t-3}}$ & $x_{2_{t-3}}$ & $x_{3_{t-3}}$ \\
\hline$\% \mathrm{e}$ & & 0.01 & $(-0.009)$ & 0.10 & $(-0.007)$ & $(-0.004)$ & 0.37 \\
\hline (t) & & 12.13 & $(-4.08)$ & 2.83 & $(-1.90)$ & $(-1.79)$ & 1.84 \\
\hline$\% \mathrm{R}^{2}$ & \multicolumn{4}{|c|}{97.4} & \multicolumn{3}{|c|}{50} \\
\hline$\% \mathrm{R}^{12}$ & \multicolumn{4}{|c|}{96.3} & \multicolumn{3}{|c|}{25} \\
\hline
\end{tabular}

المصدر : من إعداد الباحثة.

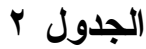

مقارنة بين بلان العينة بدون برامج الاصلاح الهيكلي للعام (؟ . . r) بتباطؤ زمني أمده

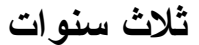

\begin{tabular}{|c|c|c|c|c|c|}
\hline & قيمة الموازين & 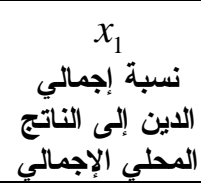 & 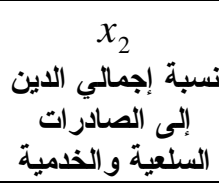 & $x_{1_{t-3}}$ & $x_{2_{t-3}}$ \\
\hline$\% \mathrm{e}$ & & 0.01 & $(-0.007)$ & $(-0.005)$ & $(-0.003)$ \\
\hline (t) & & 9.72 & $(-2.50)$ & $(-1.64)$ & $(-1.51)$ \\
\hline$\% \mathrm{R}^{2}$ & & 79.7 & & & 41.1 \\
\hline$\% \mathrm{R}^{1 / 2}$ & \multicolumn{3}{|c|}{74.6} & & \\
\hline
\end{tabular}

المصدر: من اعداد الباحثة.

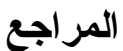

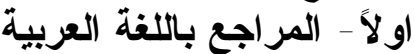

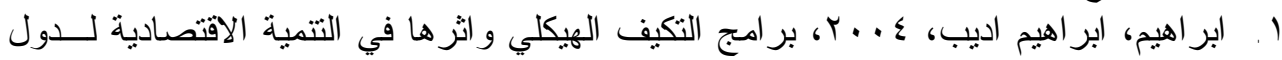

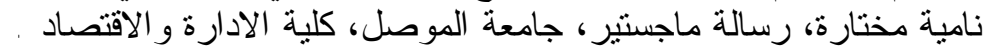

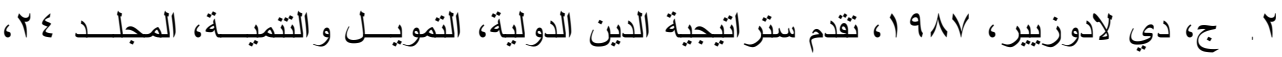

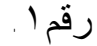
r. ج. جامعة الدول العربية، النقرير الاقتصادي العربي الموحد، اعداد متفرقة .

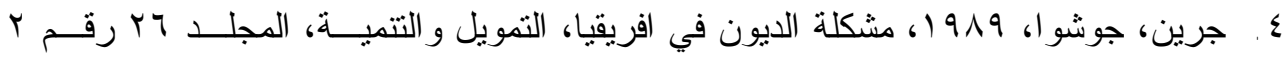

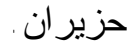

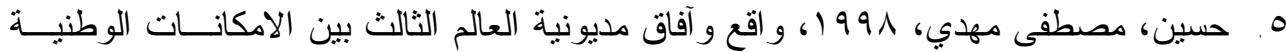

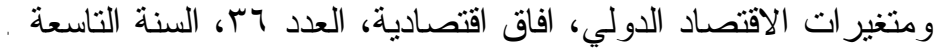

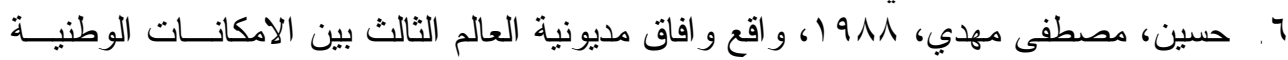
ومتغير ات الاقتصاد الدولي، افاق اقتصادية، العدد با، السنة التاسعة . 


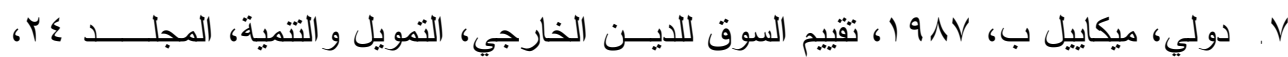

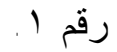

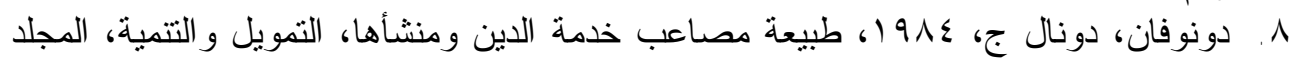

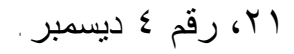

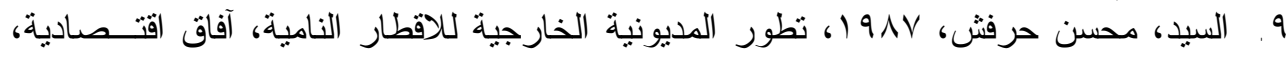
العدد با، السنة الثامنة.

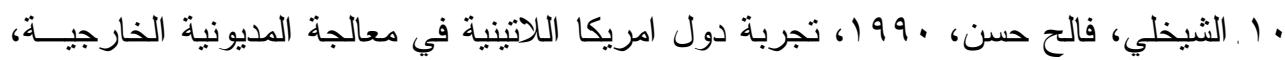

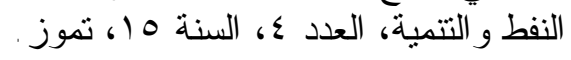

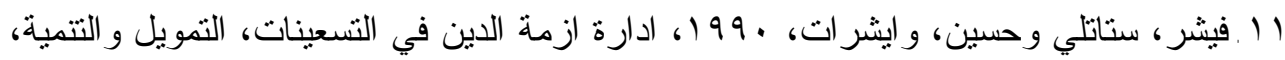

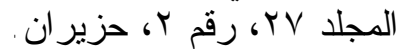

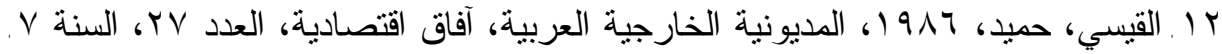

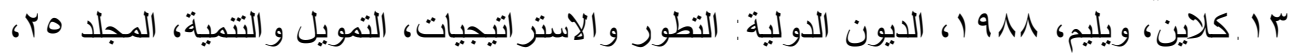

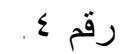

ع ( كنونة، امين رشيد، ،99 19، حلول مشكلة الديون الخارجية للبلدان النامية، تتمية الر افـدين،

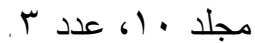

1 اـ المديونية الخارجية في البلدان النامية، عبد الرحيم محمود، المكتبـــة الالكترونيــة، المكتبـــة

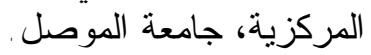

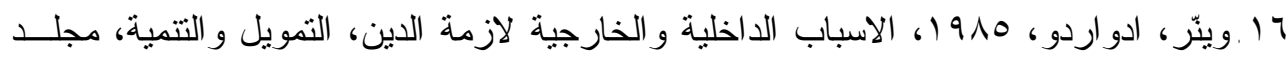

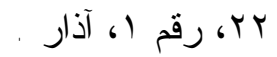

ثانياً - المر اجع باللغة الأجنبية

1.Eaton, Jonathan, 1993, Sovereign Debt: A Primer, The World Bank Economic Review, Vol (7), No. (2), Cd: 155.

2. Levine, Ross \& Scott, David, 1993, Old Debts And New Beginnings: A Policy Choice In Transitional Socialist Economies, World Development . Vol (21), No. (3), Cd: 154 .

3. Sohn, Chan - Hyun, 2002, Corporate Debt Resolution And The Role Of Foreign Capital In The Post Crisis Restbucturing Of The Republic Of Korea, The Developing Economies .. Cd: 399 .

- www : World Development Indicators Database .

- www.ibisonline.net / Research-Tools / Glossary / Glossary Disspgay Page .aspx?Termld $=1914-35 \mathrm{k}$.

$$
\text { - أديب، عبد السلام، المديونية الخارجية و العولمة. }
$$

- www.arab-api.org/course26/c26-index.htm=16k

$$
\text { - العباس، بلقاسم، ادارة الديون الخارجية . }
$$

- www.aljzeera.net/NR/exers/68071844-1582-41C4-A43C-3095F

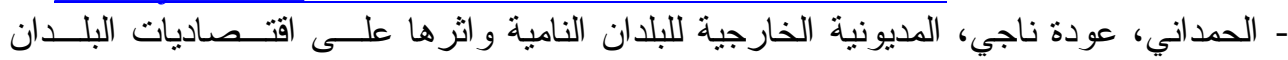

- www.rezgar.com/debat/8howart.asp?aid

$$
\text { - علي، مغوري شلبي، شروط الديون الخارجية. }
$$

- www.aljazeera.net/NR/exeres/25201447-A101-418E-90EA-25436E72572B,htm .

- www.orientation.tn/MESORIENT/ar/guidefil/6a/14.htm-12k .

- www.arab-api-org/course4/04-1-1.htm-13k . 